\title{
Energy Storage and Transfer with Homopolar Machine for a Linear Theta-Pinch Hybrid Reactor
}

by

H. F. Vogel

M. Brennan*

W. G. Dase*

K. M. Tolk*

W. F. Weldon*

*University of Texas, College of Engineeinin, Austin, TX 78712.

An Aftirmative Action / Equal Opportunity Employer 
This work was supported by the US Energy Research and Development Administration, Division of Controlled Thermonaclear Restarch.

Printed in the Unjted States of America. Available from Naticial Technical Information Service

U.S. Department of Commer a

5285 Port Royal Road

Springfield, VA 2216!

Price: Printed Copy $\$ 4.00$ Microfiche $\$ 2.25$

Thin report was prepaped an an account of work tpec. corred bo the United Silate Government. Neither the Univied Silnte:

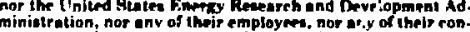
irectork. eubromirectors, or their employe makes ony

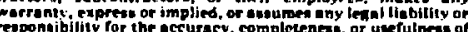
responnibility for thr eceuracy. eompleteness. or usefulness of repremente that ite use would not infringe privetely owned 


\section{contrivits}

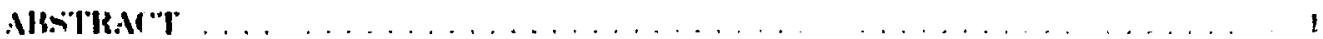

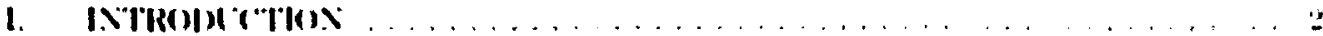

A. Sintem Dist tiselun . . . . . . . . . . . . . . . . . . . .

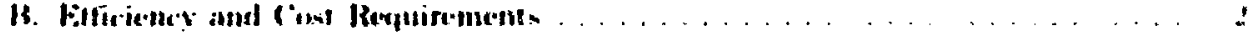

1. Circuil Allornalike. . . . . . . . . . . . . . . . . .

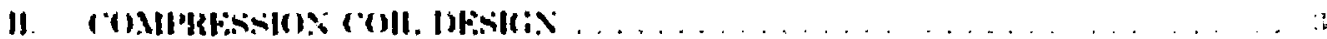

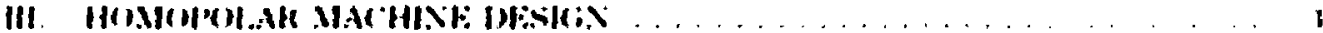

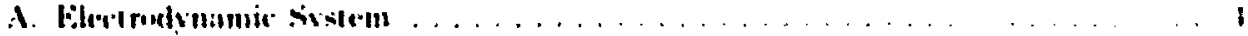

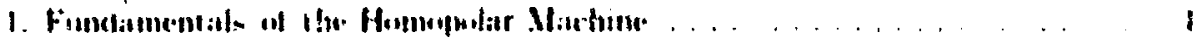

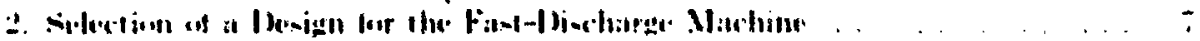

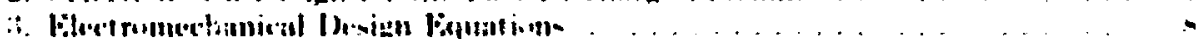

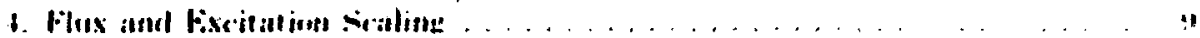

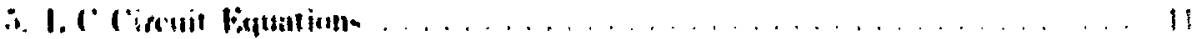

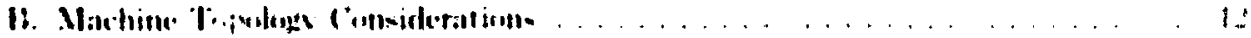

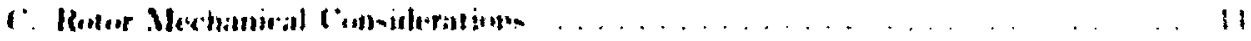

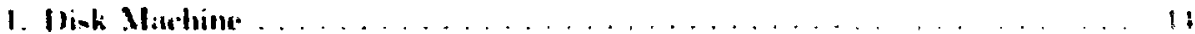

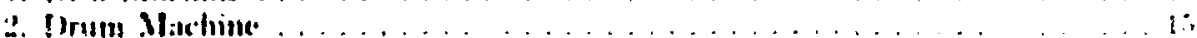

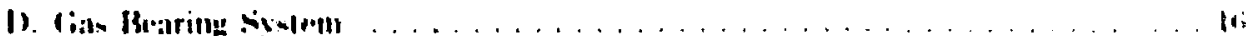

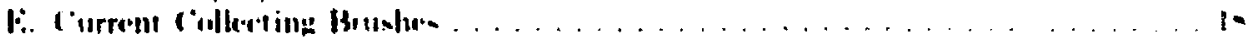

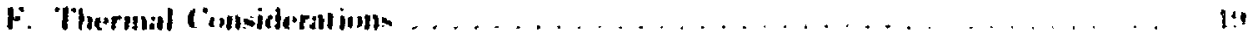

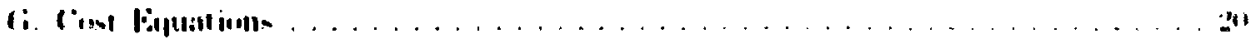

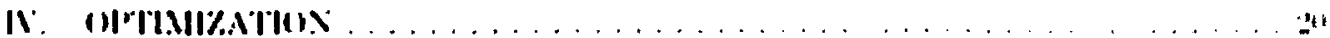

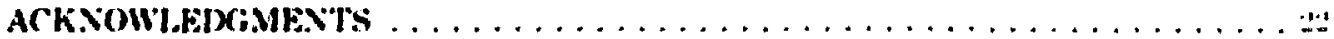

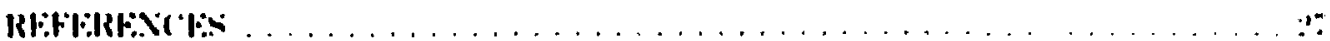

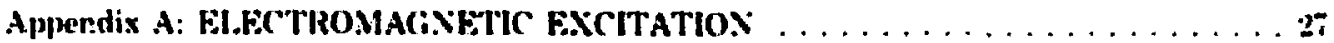

Appendix B: NORMAIJYATION OF THF EFFICIFNCY-IS.DISCHARGF

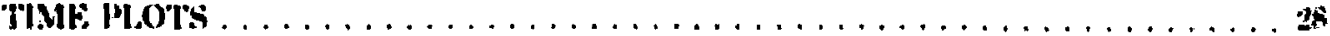




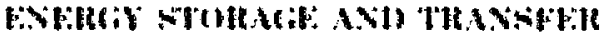

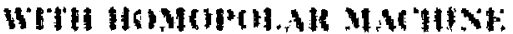

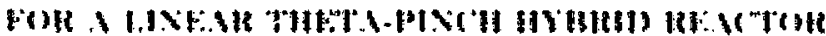

bx

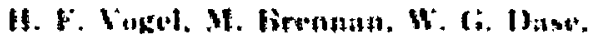
k. W. Tulk, and W. F. Wirlen

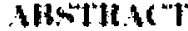

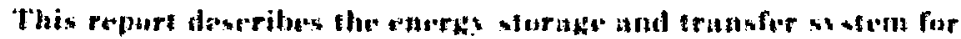

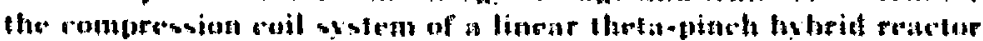

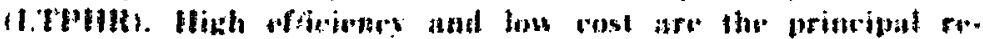

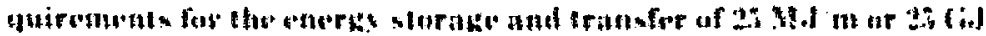

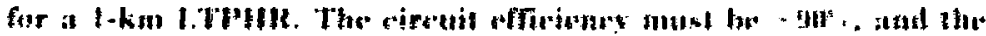
cost for the circuit $5.6 \mathrm{e} / \mathrm{J}$. Scaling law and staple relationships

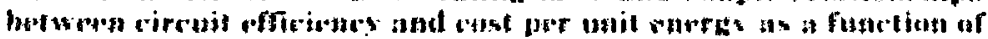

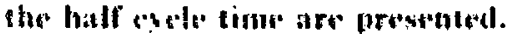

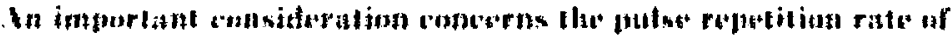

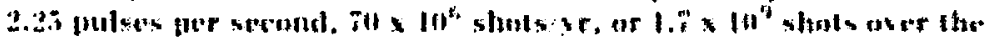

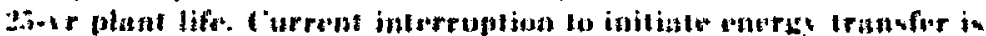
nut feasible at this rate. We consider, therefore, a simpte ringing

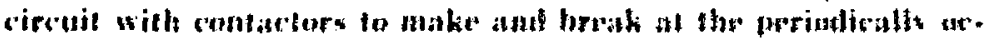

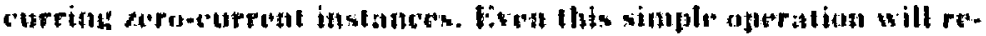
quire ronsinferable deselonetent effurt for an imexpensise and reliahle contactor that may he rephaced during annat plant mointemances.

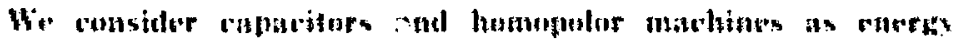

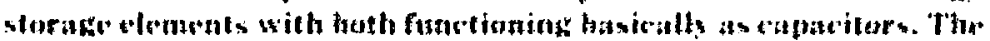

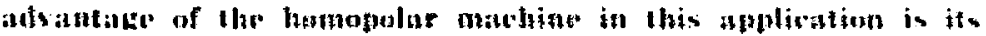

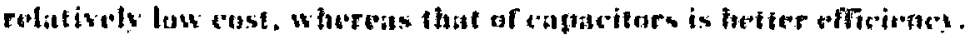

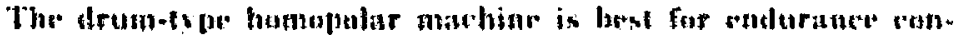

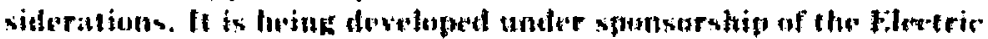

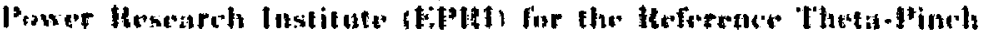

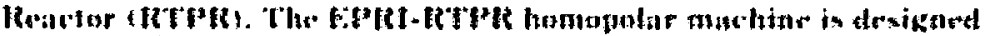

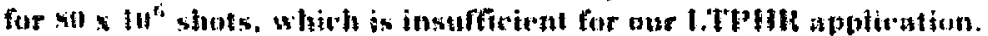
The neressart improvement in endurance is athiesud for the

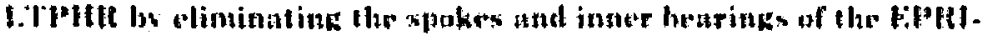

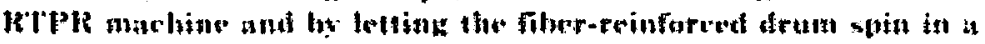
concentric besing housing. Gan is required as the bearing lubricant because of the zelatively lurke benring diameter as compazed with inner bearings supporting the drum with spokes, and because of the required low loss.

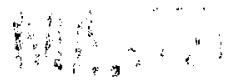




\section{INIK()) :("TIOX}

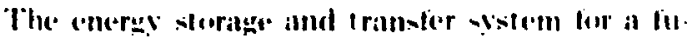
-ion hohrid reactur is chararterized by Iwo

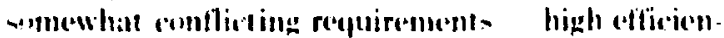
co and lew ront. The former results trom the prese. quisile positive energy balance atnd the impurtince if misimbzing enesos hes: the latler reflects the pratedienl print of view that the investument per

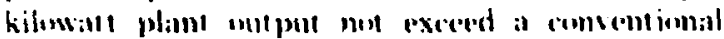

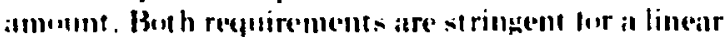

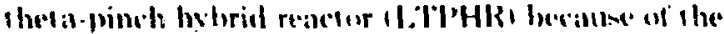
larpe magnitude of energe on be trilnsterred in and

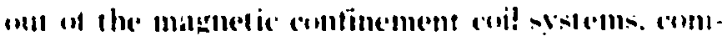
pared with the part of the masnetic energer actualls. interatelinis wilh the plasmal It this report, the fincus is an problems concerning energy transter and

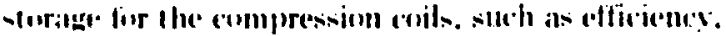
cust. and reliability

Inrent...en exi-1 for solving these problems.

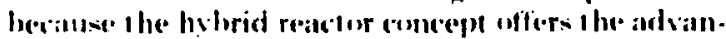
tatge that the plasmal continement time and density

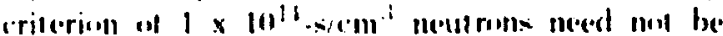
-ill istied ats in a pure fusion reitelur. This primeiple is workable an long is the neut ron flus interact ing with

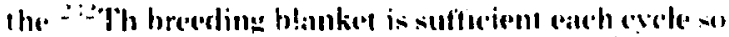

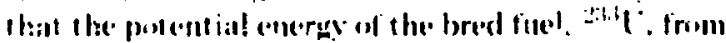
the $T h+n-2 i s u$ reaction and of the thermal output (likewise deposited in the breeding blanket) overbalances positive energy with the sum of all losses, and as long as the cost criterion is satisfied. Many additional criteria. such as operating reliability. feasibility of materials hat.Aling. and environmental compatibility, must also be met.

\section{A. Sysstem Diseussion}

A single.coil energy sturnge and transfer spistem

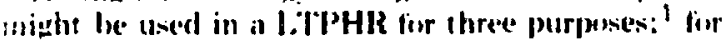
impleswion healling and slaging of the piasmal and leor allathatic compression during phasma burn time. which immerlialeds follows the implesion heating and st atuing. Implesion heat ing requires a $0.1-\mu$ s field

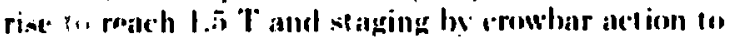
mantain the marnetie field until it hecomes enhanced be the adiabatic compression lield. Approximately f(x) $\mathrm{k} \mathrm{V}^{\circ}$ for a single-1 urn coil of $20(x) \mathrm{kl}^{\circ}$

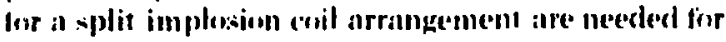
the lisst fiedde.

The in elo loss in the leats beconase excessive if the implusion coils arre alson used for compressiun. The luss is extessit be becollse the magnet ic lield repuirem(nt is high 125) 'T. which implies an excitation current of $-4.6 \mathrm{MA}$, and the coneryy transfer time is short 1 - 1.5 m.1, resulting in excessive eddy losses in

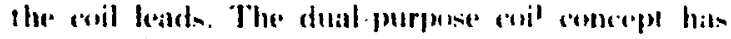
therefore been absondemest. and a separate multiple.

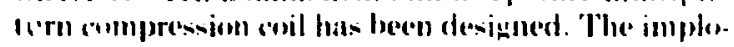

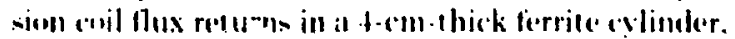
which separates the compression conil tromi the im. plasion coil. In this design the energy requirement fin the compressim coil is al factur $i . s$ greater thatn

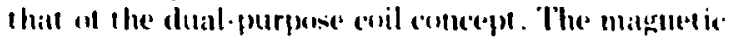

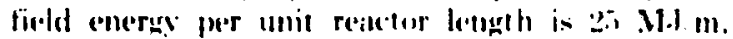

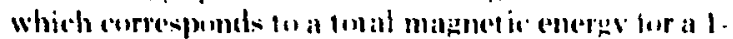

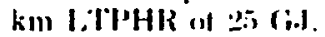

An important consideration in this studs ronterm-

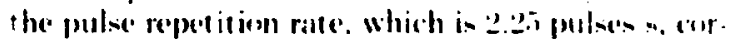

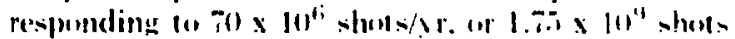

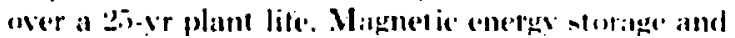

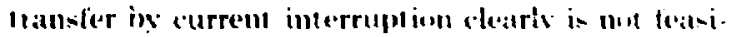
ble in this applieat ion. The propened cirerut in 1 he $l$. 1 ringing cirenit. shown in Fig. 1. in which the switch edoses and opens an chese as pomible io the rimes al which the purrent genes through aerw. This "perat in will require comsideratble - witeh develop. ment so that an inespensice and reliable comtike!or berolles acidilable that can be replated durine an. nuil plant mainsenance. The propmeded crete is alsol shown in Fig. 1.

\section{Hifneieney and Cost Requirements}

Pigsure 2 shows a sislem energy tlow diagratm.

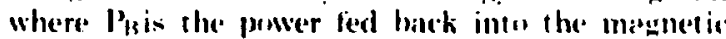
field coil swstem dimplosion st aging and compression

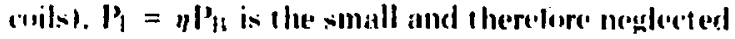

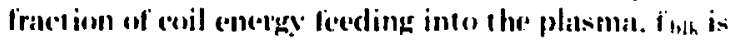
the joule less in the eroils that may be recowered as part of blanket heat. and lis is the joutle hass in the externali elecet ric circuits. such as power stlpple less and capacitor loss. nul': !: : hat part of the matghet is field encergy restored it the external elece ric cirenis.

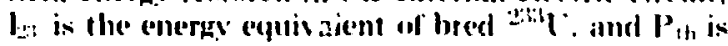
thermal energy remored from the ireeding blanket.

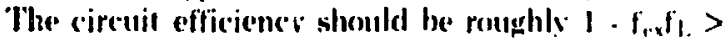
II.9.

Typicalis, a 1-km I.T'ilts bas an IR-metric ton londing of 2 :s 1 ' with a doubling time of 11 srs, which rorresponds to an electrical power ontent from the integrated sistem of uranium burner and converted heat from the blanket of $T$.t Givie. The tortal plant

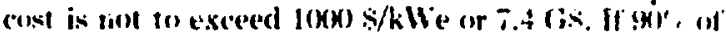
this cost is mereded for plant eomponents other than the eompress on coil capacioor hank. 'hen the capacitor bank should not exceed a rost limit per unit stored enerdy al $5.3 \mathrm{~d} / \mathrm{J}$.

"These numbers may serve as guidelines, hut need exists firr an efficiency-vs-cost relation:ship that can be used for optimizing the overall LITPHI? sistem. 

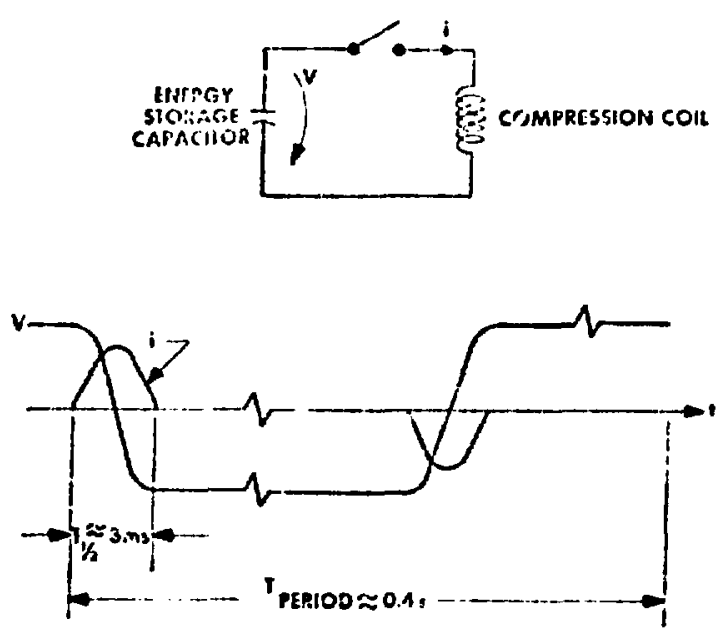

Fig. $l$.

Compression coil circuit.

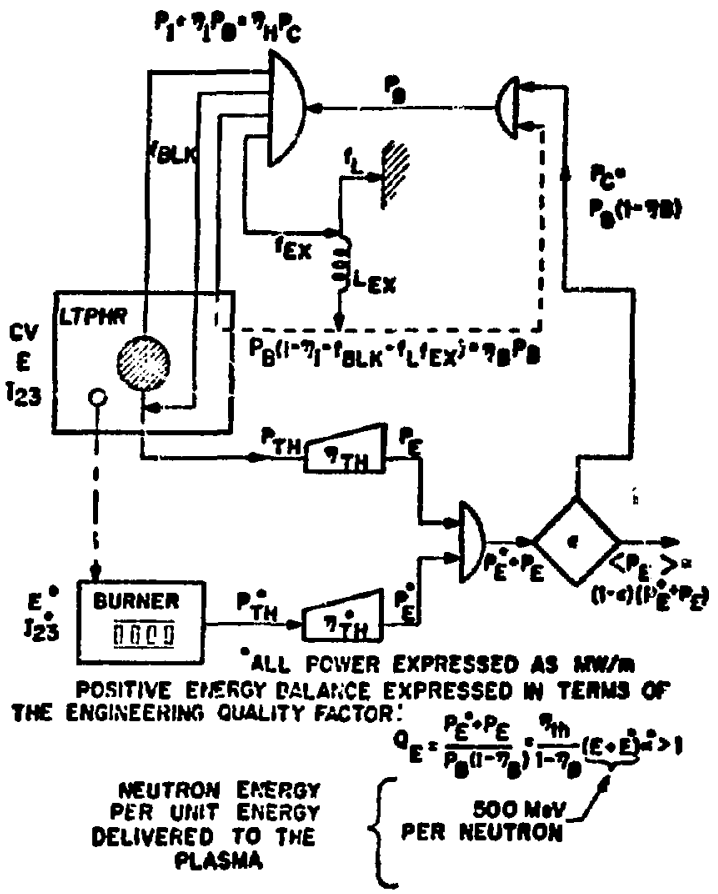

Fig. 2.

LTPHR energy flou dingram.

This report addresses this need. and the desired cont-eflicieney-transfor time relationship is developed in Sere. 11.

\section{Circuil Alternglives}

For the given pulse rate. we consider onls the simplest type circuit requiring no current intermption. This eireuit causes vollage reversal of the eneras sturage capacitur. It seems unlikcls that rapacitors designed for this operation and for ac nervire life (an be develoned so that the inst alled (ort diess non esceed the cited eosi limit per unit stored energey. However. we will show that homopular machines can be built for this uperation and meet Hee cont criterion. ald hough the efficiency criterion sem- onls marpinally satisfied. For capateitors. we assume 1 - fi. $h_{1}=0.64$ and $14 d / 3$. Overall syolem analswis is 11 determine whelher homopolar markhines or raparciturs best sorse the recpuirementin the I.TTHK.

\section{H. COMPRESSION COII. DESITIN}

The compression coil dexign is determined by the follewing paramelers.

Inside radius: $1.4 \cdot m$ li.e. inner wall radlius $=111+$ t $\cdot \mathrm{m}$ implesion henting coil and hux returnt.

Magmetic mux dersity: $20 \mathrm{~T}$.

Minimum coil height requirement lo whatan minimum magnetic field energy and minimum meutron alsorrpution in the coil.

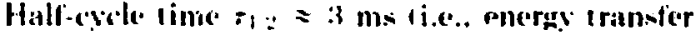
lime calpacitur-lon-coil and batekl.

Inule lons of the coil leads i hrumgh the hankel 11 . m lengthl and wat wo the homegsolar matehine tad. ditimal 1-m lengtht should be as small as posithle consistent with other rapuirements.

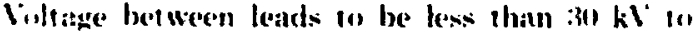
keep) the insulation recuuirements on the leads and the lesol inductance small.

Adecluate st ructural endurance characteristies.

One design seems to meet the abure refuirements. It is described below and camensioned in Fiz. it.

Sumber of turns per coil: 10

Coil current enreeponding to $25 \mathrm{~T}$ : 0.4ts . MA

Number of fully transpussed conductor st rnucts: s0

Coil inductance: 5is.5 $\mu \mathrm{H}$

Pulse resistance: ilis $\mu$ !

dr resistance: : $368 \mathrm{\mu}$ !!

Comductor length for 10.turn coil only: $12.0 \mathrm{~m}$ : for 2 leads: $+\mathrm{m}$.

The coil leads are fastened to plugs, shom in Fig. 4. which allow removal of the blanket with coils and vacuum chamber in $1-m$ sections.

Fach of the 30 conductor simats comsists of magnet wire $1.9 \mathrm{by} 9 \mathrm{~mm}^{2}$ clad with $0.4-\mathrm{mm}-1$ hick stainless sleel for increasing the endurance 


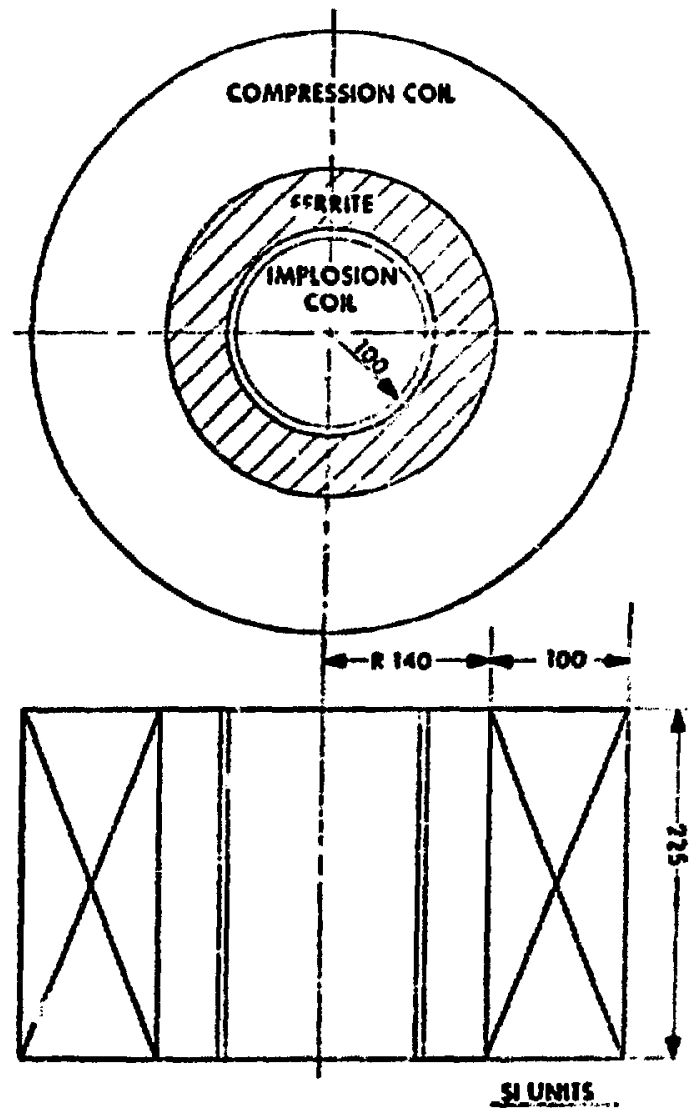

Fin. :

L.TPHK masnetic confinement coils.

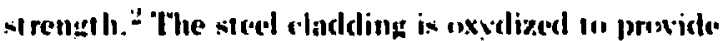
neyligrible intersil rand condituctance.

\section{HOMOPOIAR MACHINF DESICN}

The oferating principle is explained and the design copuntions are devele peed in the firilowiong sullo. sectiuss on the hemopolar machine and its sulb.

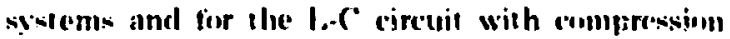
criils.

\section{A. Flectrodynamic System}

The electrorlsnamie system treited here includes. the equations fir the L-C circuit.
1. Fundamentuls of the Humopular Machine. A voltage is induced in a closed circuit (i.e., a conductor) moving with respect to a homogenerous magnetic field, as shown in Fix. 5. This effect is used in eddy current brakes, where the emf induced in the con. ductor shown in Fig. is will produce eddy currents. which in tum interact with the magnetic field. thus causing the motion to be resisted in accordance with Lenz.'s law.

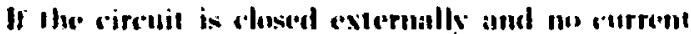
path exists. lluen all emet is induced, and "m.

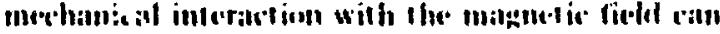
cccur i.e., no "braking force" exists). This is true for the runfiguralion sluwh in Fig. $t$ and

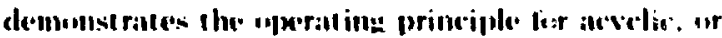

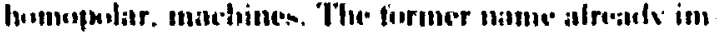

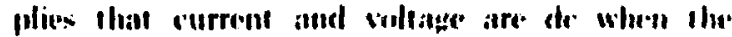

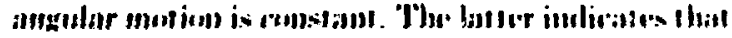

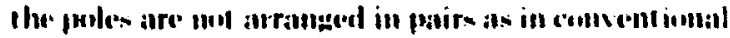
dc machines. but as if the magnetic pole were inside the spinning cylinder. with the pole of opposite polarity at intinity. In other words. the magnetic hux returns are not germane to the operating principle and could be omitted if sufficiontly strong maknetic monopoles existed.

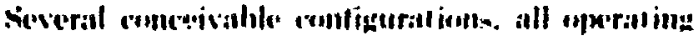

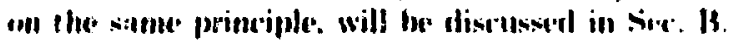

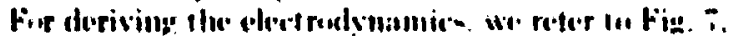

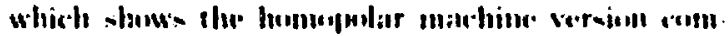

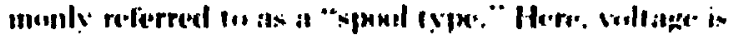
indeced in ihe itram and in the disk like rends, all in

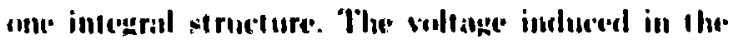

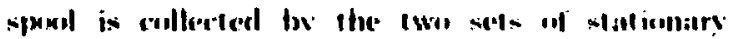

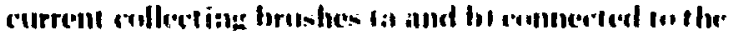

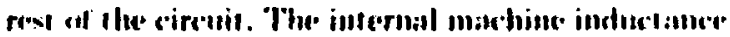
is minimizad by the refurn comductor sersing an current relurn comerentric sith the rulor.

The litus intereconting the retlon is clerived in Appendix $A$ ils

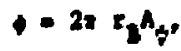

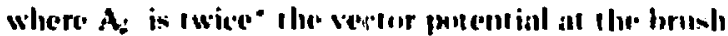
with $A_{1}=0$ loging defined on the axis. and wish ry loving the radius of the current coullector surfines. The voltange lectween bresileses and b is derisend from Faraclays: law in . Ipmendix A. i.e..

$$
v_{a b}=d u / d t,
$$

Turce because the potential $1_{3} A_{4}$ exists at brush a. and $-\frac{1}{2} A_{t}$ at irush $b$, and opotertial on the axis. in Fin. 7. 


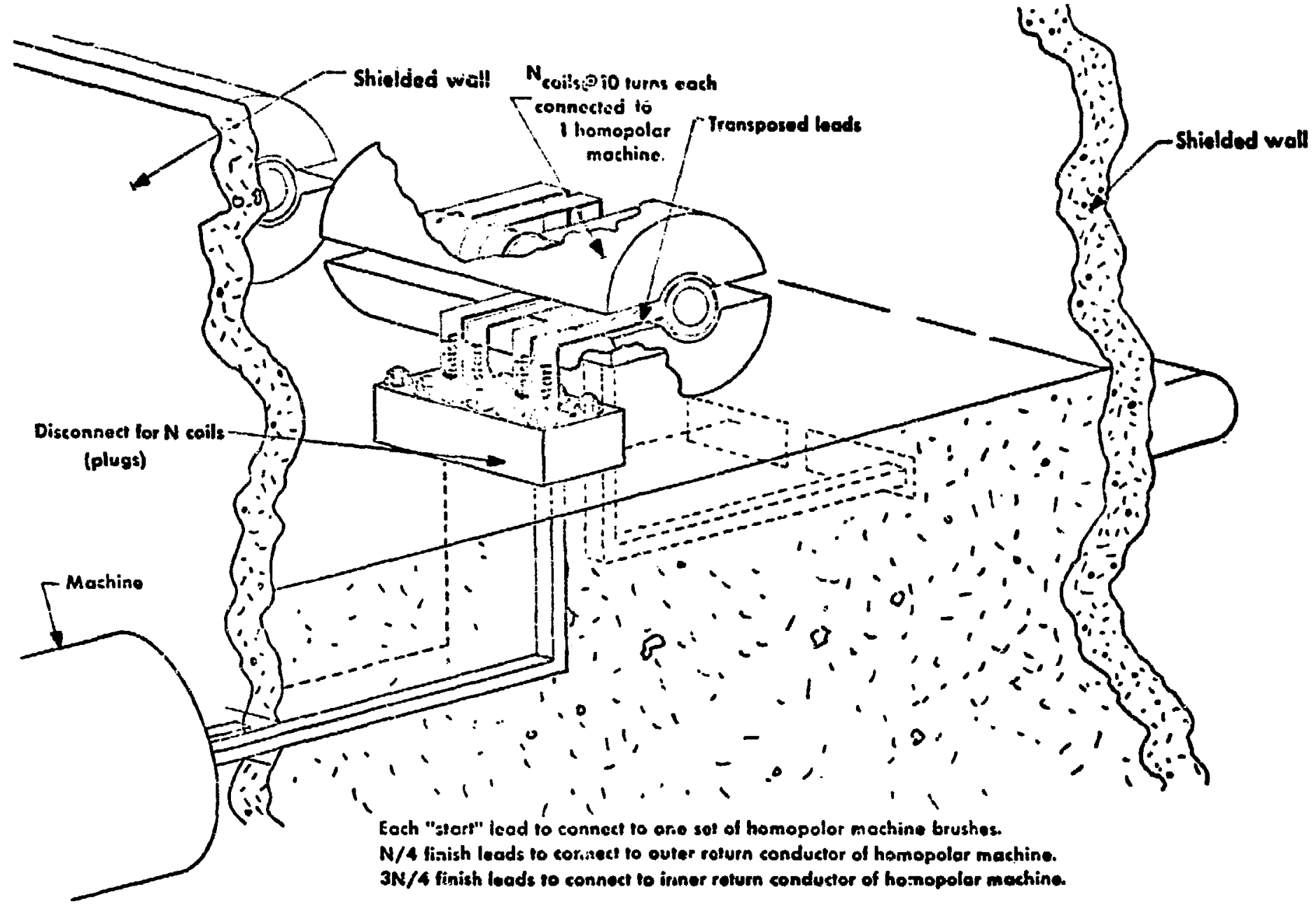

Fig. 4 .

LTIHR compression coil asse'mbly. 


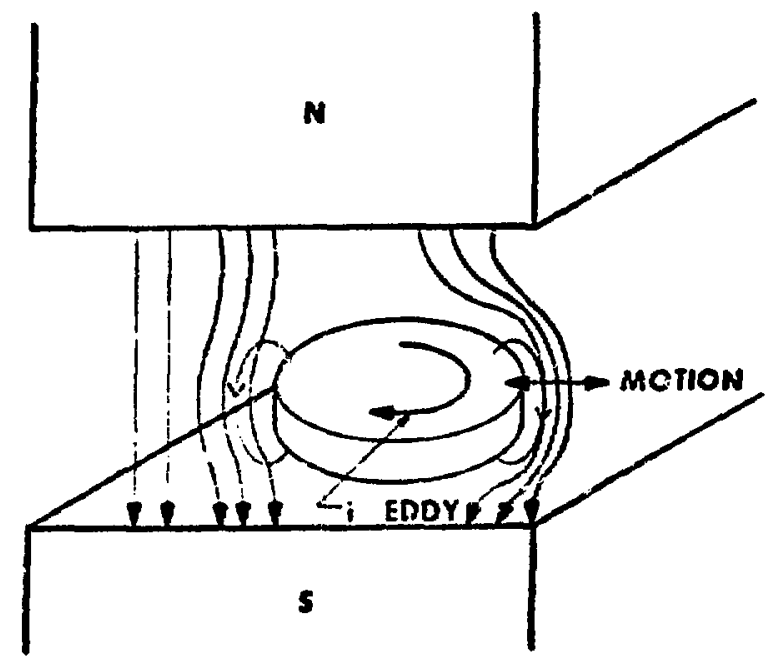

Fig. 5.

Conductor with internally closed circuit moving in a homogeneous magnetic field.

which indicates that the potential is arimbathalls directed. and whe ise $0^{3}=2 \pi A_{\text {. }}$.

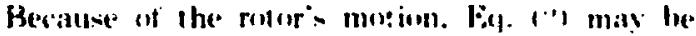
written as a parlial differential equatlien with time and spattial deriva:ise.s i.t'..

$$
\frac{d t}{d t}=\frac{\partial \phi}{\partial t}+-\frac{\partial \phi}{\partial \psi} \text {. }
$$

where

$$
\omega=\frac{d v}{d t}
$$

For stealy-itale altgular motion. we hatre $\partial \phi / \partial \psi=$

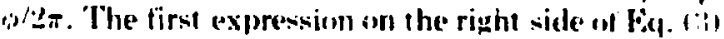
i. zero tor de excitation d = constant. Fguat ion 12? may thus be rewrilten as follews for do excitaltem

$$
v_{a b}=-\frac{\mu \phi}{2 \pi} .
$$

Fquation (5) is the well-known operating equation for the homopular machine. Substituting E.y. 111 in Fq. (i) : ¿...

$$
v_{a b}=-w\left(r_{B} A_{\psi}\right)
$$

shows that the voltage is a function of only the angular speed $\omega$ and the radius-corrected vector potential $\left(n_{3} A_{4}\right)$ at the collector. Therefore. both
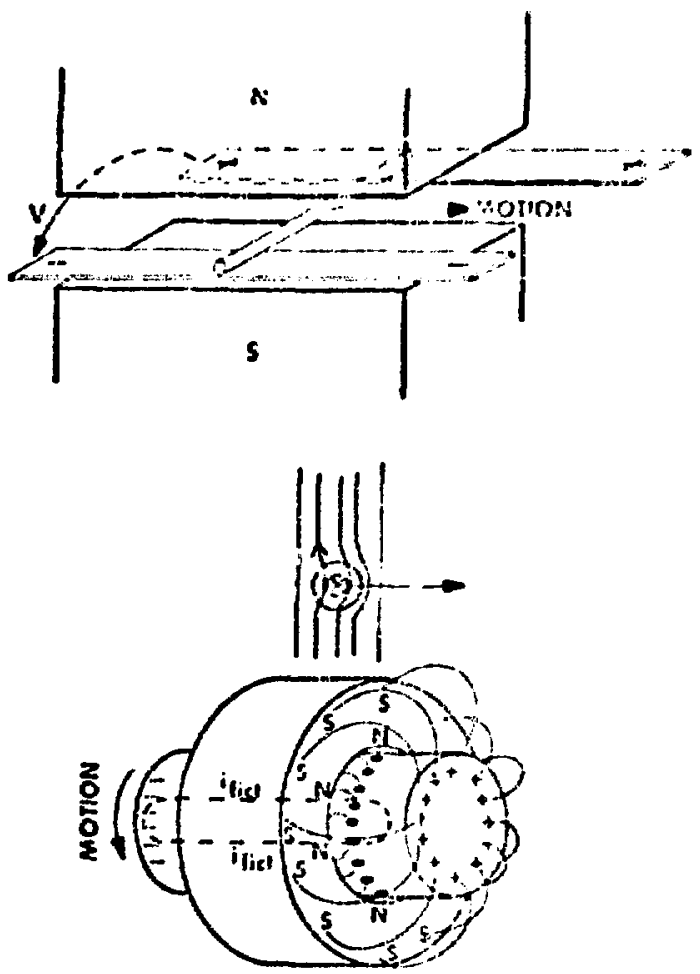

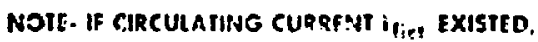

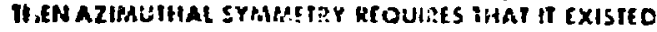

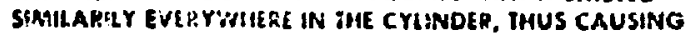
SELF-CAHCELAIION.

Fin. is.

('omduction with extornai circuit refurn mosing

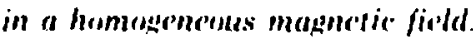

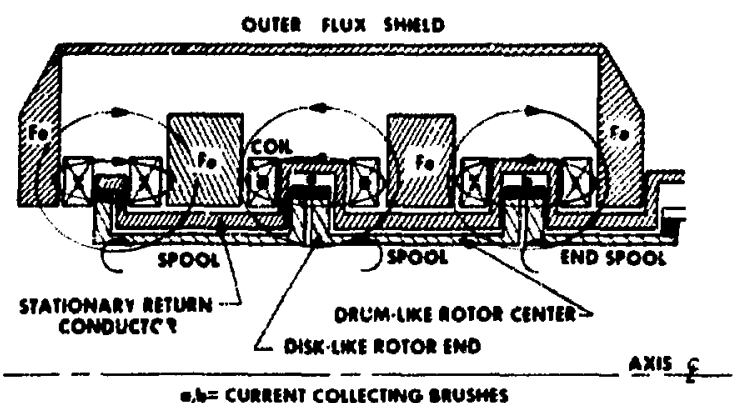

Fig. 7.

Homopolar spool-type machine. 


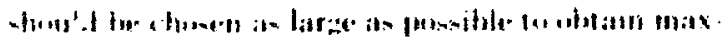

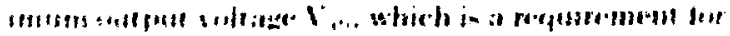

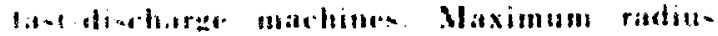

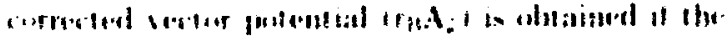
flin then-112

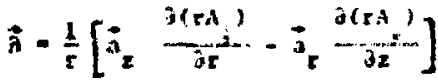

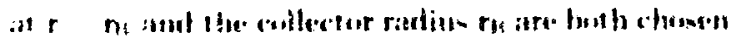

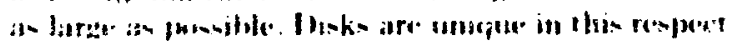

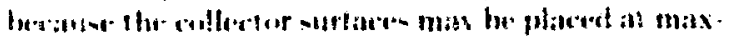
Imms! furtatutal

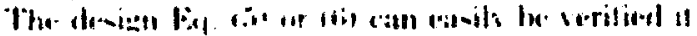

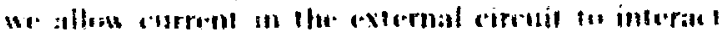

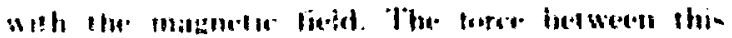

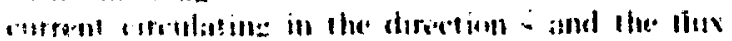

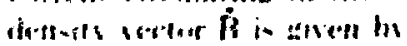

$\vec{F} \cdot I \int \mathrm{d} \times \overrightarrow{\mathrm{E}}$

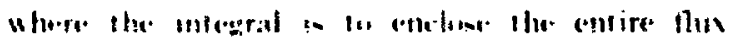

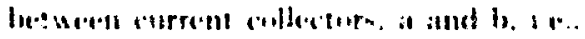

$f d \vec{B}=\frac{t}{2 \pi r_{B}}$.

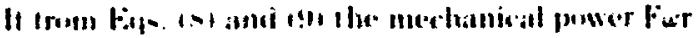

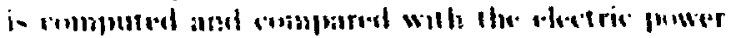

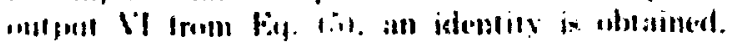
whints werses as merilicalion.

\section{Sicleetion of a Design for the Fust-Discharue}

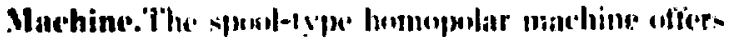

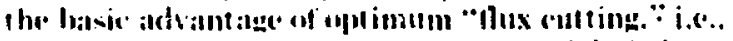
|riat = maximum. A severe mallerial tolligue prohleyn exists. henwerer. which will lo discussed in sere. 1". This cendurane quest ion the's mol exist in the silme severity lior the drum rotor. in which the bru-les slida an a estindrical drum. as shown in Fig. A. Here the drum. carrying virtually unifurm current den-ity. interacts with the magnet ic tield whose Mux density \& saries liftle in the axial direction and nut al all in the azimuthal direstim. The stress to be transmitced in the elrum is therefore small, and mo stress concentration exists such as the sno in the drum-lo-dist 'mansition of the spunl machine.

He will show in Sies. A.3 that high speed and low menment of inertia are elesired for the rolor of a fast discharge machine. I,ow-density materials such as ahuminum should therefore be chosen for the drum. If the drum is wrapped with a high-st rength mat eri-!l such as the wraphite-filament/apoxy composite dis-

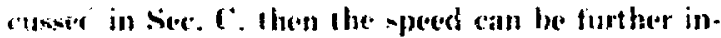
creasicel with the incriat increasing binle.

Gme of the majur comalderations in selectiag a sijtable design is loresh frietion loss. It is advan.

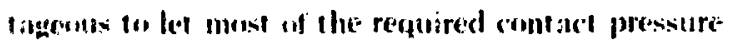
ho provided be olect rodsanmis interaction bet wash truah current ind he magnstir leakigge field

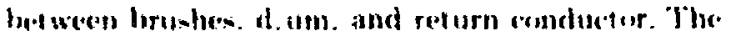

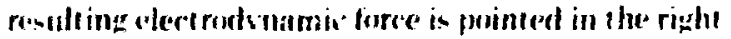

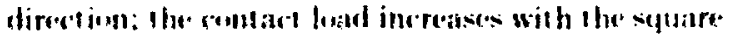

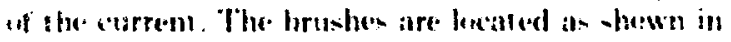
fistis.

For al given quabuets the thux increases with the

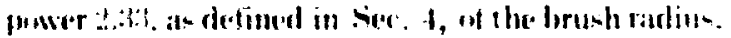
in...

$+E_{8}^{2.33}, x_{0} \cdot\left(x_{1}\right) \cos 1$.

11611

This is at zened reasion for piacing the current reilum itside the drum. the to elimating the need to in.

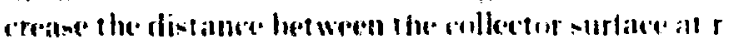

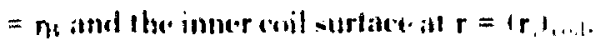

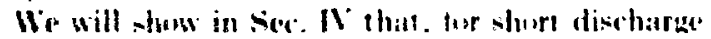

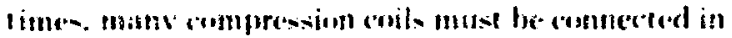

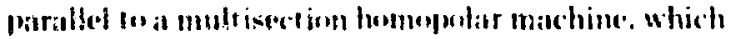
math resuls in several mesalmperes of discharge

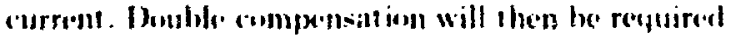

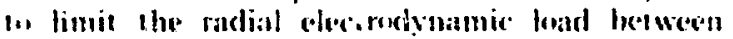
rentern enciuctor and drum. More than balt the eturrent will return through the inner return andue. for and the balance will return threngh the ad. ditiona! enasial path in the spare herwerl coil and drum as -husan in Fig. 9.

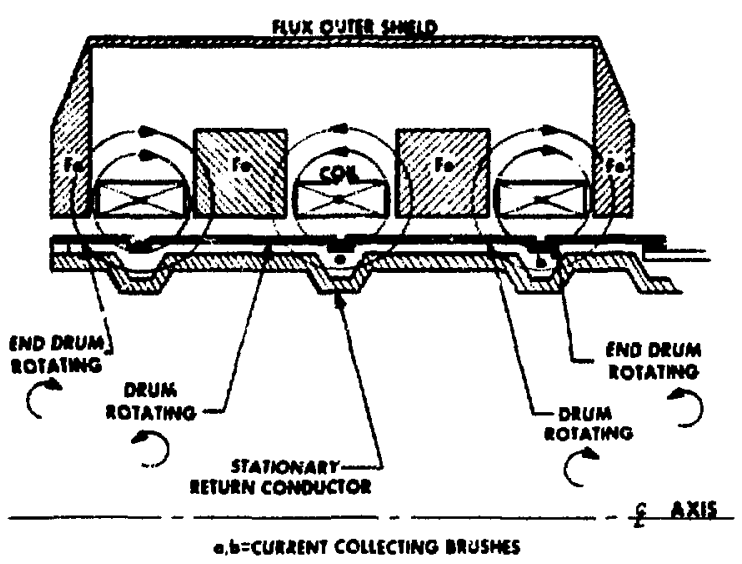

Fig. 8.

Homopolar drum-type machine. 
3. Flectromechanical Design Equations.W، write the design equations with notations for the linear dimensions, resistances. and inductances as defined in Fig. 9 for the machine with drum rotor. the electrodsnamic forces on the rotor will be treated in Sire. C.I The iron shown in Fig. 9 minimizes reluctance of that path of the maynetic thux that intersects the rotor. The outer iron shell is only to contine the llux for environmental sifecty. Figuations whose derivat ion is trivial are given in the following list without derivation.

Refurn conductor resistance:

$R_{12}=P_{12} \frac{l}{r_{2}{ }^{2}-r_{1}^{2}} \frac{1}{\pi}$,

whore

$\rho_{12}=\rho_{c u} \frac{234.5+T}{254.5}$.

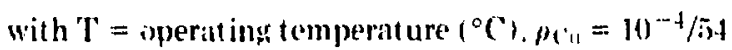
!? เm:

Drum resistanc:

$$
B_{34}=\rho_{34} \frac{Q}{r_{4}^{2}-r_{3}^{2}} \frac{l}{\pi}
$$

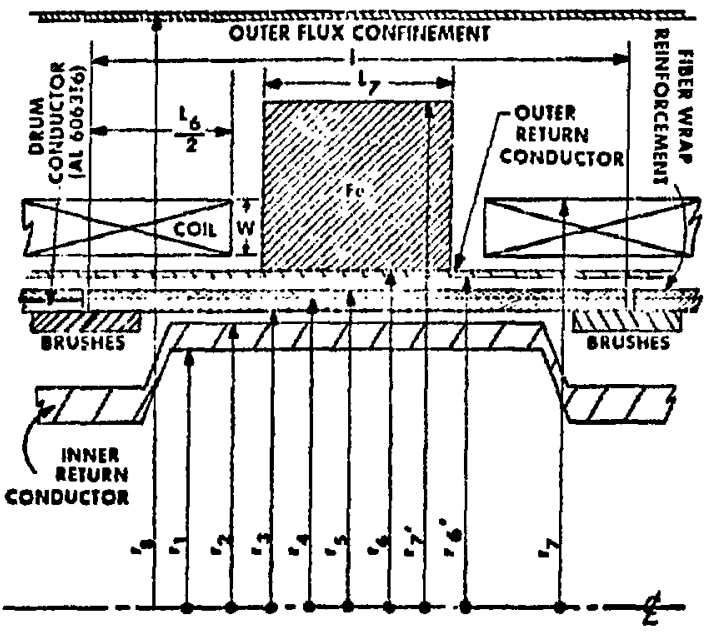

Fig. 9.

Definition of dimensions for the drum-type machine with doublo compensation (i.e., inner ond outer current return). with

$p_{34}-f_{A 1} \frac{234.5+x}{254.5}$

$P_{A 1}=10^{-\omega / 30.5} \Omega \mathrm{cm} ;$

Refurn conductor inductance:

$L_{12}=\frac{\mu_{0} l}{2 \pi\left(r_{2}^{2}-r_{1}^{2}\right)}\left(\frac{r_{1}^{4}}{r_{2}^{2}-r_{1}^{2}} \ln \left|\frac{r_{2}}{r_{1}}\right|-\frac{3 r_{1}^{2}-r_{2}^{2}}{4}\right) \cdot$

where

$\mu_{0}=0.4 \pi 1 \cdot 1.0^{-6}[\mathrm{H} / \mathrm{m}]$

Inductance of the return conductor-to-drum interspance:

$L_{23}=\frac{\mu_{0} \&}{2 \pi}-\ln \left|\frac{r_{3}}{\tau_{2}}\right|$.

Similarly, for L L

Drum inductance:

$z_{34}=\frac{\mu_{0}{ }^{2}}{2 \pi\left(r_{4}{ }^{2}-r_{3}{ }^{2}\right)}\left(\frac{r_{4}{ }^{4}}{r^{2}-r_{3}^{2}} \ln \left|\frac{r_{4}}{r_{3}}\right|-\frac{3 r_{4}{ }^{2}-r_{3}{ }^{2}}{4}\right) ;($

similarly for $\mathrm{L}_{4 i} \%$

Moments of inertia:

Drum:

$\theta_{34}=\frac{\pi}{2} \gamma_{34} 2\left(r_{4}^{4}-r_{3}{ }^{4}\right)$.

where

$\gamma_{34}=2.71 \mathrm{~g} / \mathrm{cm}^{3} ;$

Fiberwrap:

$\theta_{45}=\frac{\pi}{2} \gamma_{45} 2\left(r_{5}{ }^{4}-r_{4}{ }^{4}\right)$, 
where

$Y_{45}=1.66 \mathrm{~g} / \mathrm{cm}^{3} ;$

For the entire drum:

$\theta=\theta_{34}+\theta_{45}$.

4. Flux and Exeitation Sealing. The proportions of coil and iron have empirically been optimized to within a lew percent of an apparent optimum, with the aid of the maunetic field design code POISSON. The coil's inner radius was kept const ant at $r_{6}=118$ ('m. whereas the ratio of iron length to coil length and the total sector length $/$ were varied. We assum ed that the coil was enclosed in a toroidal dewar with 2.5-('m whil thirkiless. 2.1$)$ cm for the super insulation. and $0.5 \mathrm{~cm}$ for structural elements such as statinless steel walls. A flux plot for this configuration is shewn in Fig. 10.

The optimized set of linear proportions (in $(\cdot m)$ as show'n in Fig. 9 follows.

$$
\begin{aligned}
& r_{i}=118 \\
& W=18 \\
& i_{i}=113 \\
& r_{i}=136 \\
& r_{i}=170 \\
& r_{i}=109 \\
& i=228 \mathrm{~cm}
\end{aligned}
$$

The variable in the scaling problem for sustem optimizat ion is the linear scaling factor $\lambda$ operat ing on all linear dimensions, except the radial thickness $w$ of the excitation coil.

We denote the reference dimensions in the following by the subscript 0 and define

$\phi=$ flux effictive at collector radius.

(IN) = excitation ampere-turns.

$. J=$ excitation coil average current density.

w = excitation coil radial width. and

$B=$ maximum flux density in the coil.

Bv skipping trivial derivations. we can write the three fundamental scaling relationships

$\frac{\phi}{\phi_{0}}=\lambda \frac{\text { IN }}{(\text { IN })_{0}}$

$\frac{B}{B_{0}}=\frac{1}{\lambda} \frac{I N}{(I N)_{0}}$ where two scale variables may be eliminated in Eq. (19) as follows.

First, we substitute in Eu. (19) the J-vs-B relationship defining the limit for stable operation in the supercondusting state for :s stahilized superconductor. This may be expressed as

$\frac{J}{J_{0}} \cdot \exp \frac{B_{0}^{-B}}{\bar{B}}$

for a NbTi conductor ${ }^{3}$ with copper area to superconductor area ratio 2.9. where

$$
\begin{aligned}
& J_{11}=75 \mathrm{~A} / \mathrm{mm}^{2} . \\
& \vec{B}_{11}=8 \mathrm{~T} \\
& \overrightarrow{\mathrm{B}}=4.4 \mathrm{~T} .
\end{aligned}
$$

and where $J_{1}$ has been multiplied hy an assunied coil packing factor of 0.4 .

Second, we scale the coil's radial width $w$ with the linear scaling factor $\lambda$ by setting in. Fy. (19)

$$
\lambda \frac{w_{0}}{y}-1
$$

and inserting Eqs. (20) and (21) in Eq. (19) to obtain the set of two equations

$\frac{B}{B_{0}}=1-\frac{\bar{B}}{B_{0}} \ln \left|\frac{1}{\lambda} \frac{B}{B_{0}}\right|$ and

$\frac{\phi}{\phi_{0}}=\lambda^{2} \underset{B_{0}}{B}$.

For a given scaling factor $\lambda$, the thux density $B$ is now uniquely determined by the first part of $\mathrm{Fa}$. (22). and $\phi$ by the second part. The design-code DRIMMTYP uses Newton's method to solve the transcendental $\mathrm{Eq}$. (2.2) for $\mathrm{B}$.

The flux $\phi$ is yet to be multiplied by a correction factor to account for the fact that the space for the dewar wall must be kept constant and that there is some, although small, saturation effect. The former increases the flux density with increasing scaling factor; the latter decreases it because flux density increases with increasing $\lambda$ according to the first part of Eq. (22). This small correction was determined empirically from POISSON computations and may be written

$$
f=1.0373-0.0373 \frac{B}{B_{0}}
$$




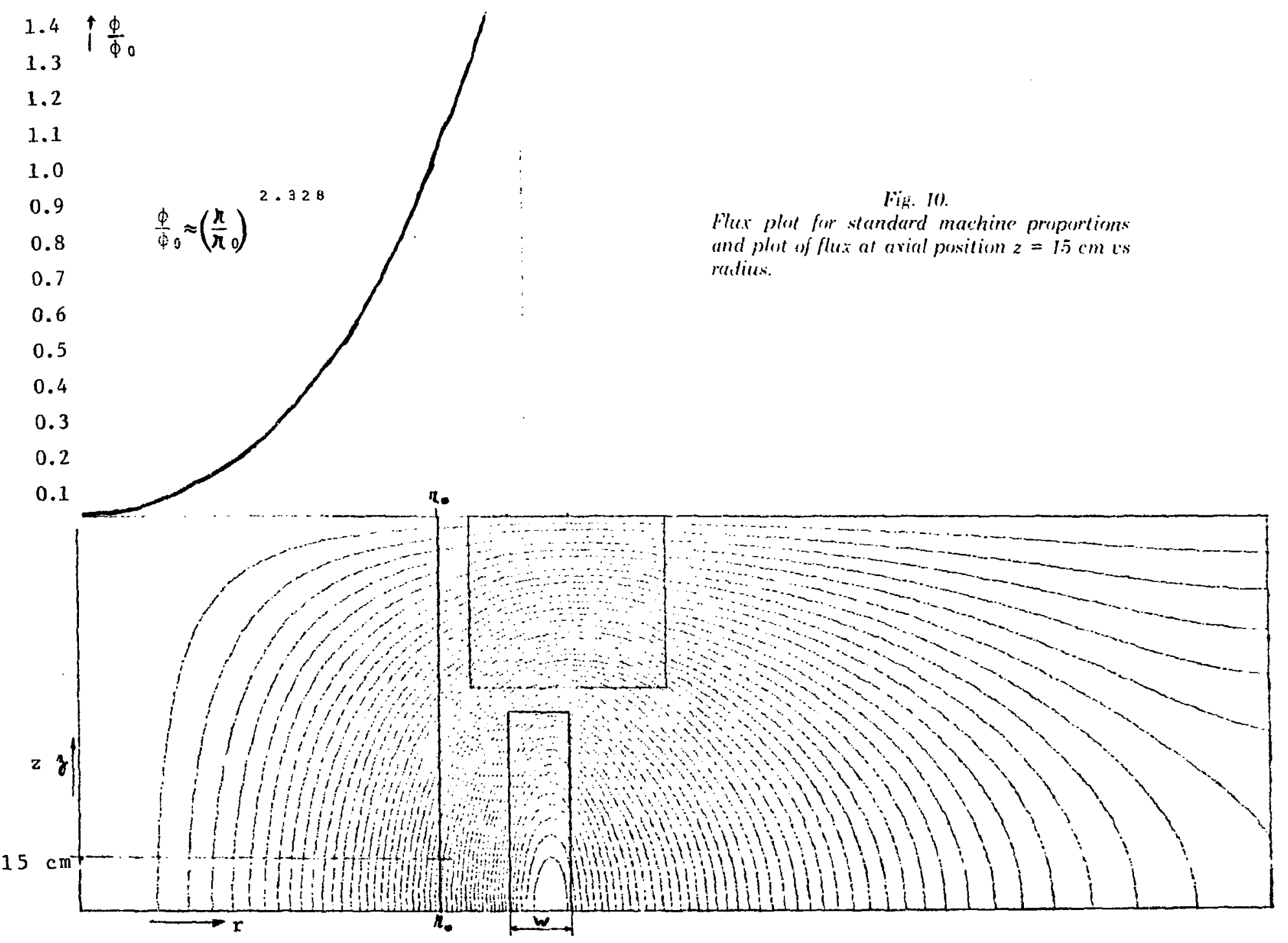


The 1lux stret $=f \cdot \phi$ obtained from Eqs, $(22)$ and (2:3) exists with respect to the lineurly scaled reference rarlius $r_{\mathrm{ref}}=\lambda \mathrm{r}_{311}$, where $\mathrm{r}_{3: 3}=104 \mathrm{~cm}$. Therefore. we must know the flux as a function of radius for the given set of linear proportions. This is shown in Fig. 10 as determined from POISSON cilculations, and may be expressed as

$$
\frac{\phi\left(r_{3}\right)}{\phi\left(r_{r e f}\right)}=\left(\frac{r_{3}}{r_{r e z}}\right)^{2,320}
$$

5. L,-C Circuit Equations. The I,-C energy transfer circuit is shown in Fig. 11, where $V_{11}$ is the initial output voltage per Egs. (5) and (24), multiplied by the number of rotors $n$ connected in series, i.e..

$v_{0}=n \frac{\omega}{2 \pi} \lambda^{2}+\phi_{0}\left(\frac{\tau_{3}}{\lambda \tau_{30}}\right)^{2.320}$,

where $d_{4_{1}}=36.3 \mathrm{~Wb}$ as obtained from POISSON.

Let $J V_{B}$ he the sum of $2 n$ brush voltage drops. each one equal to $\sim 0.8 \mathrm{~V}$ as shown in Sec. E. Let $L_{t o t}$ and $R_{n}$ be the sum of all inductances and resistances including those of the compression coil and the leads. For the purpose of circuit optimization. 10', was added to the sum of the internal resist ances of Eqs. (11) - (15) to account for lead Inss in the homopolar machine, and $10 \%$ was added to the compression coil inductance and resistance to account for its lead loss.

The equivalent caprcitance of the machine is obtained from the storell energy correspondence

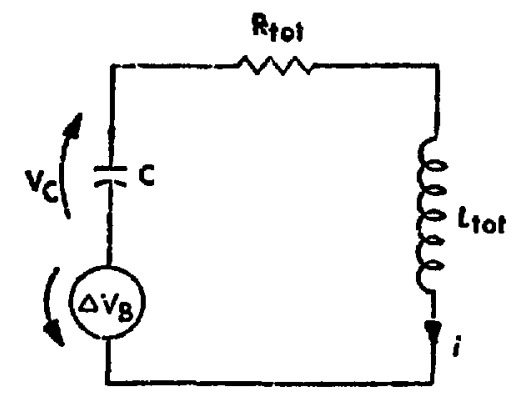

C=HOMOPOLAR MACHINE EQUIVILANIT CAPACITANCE $\triangle V_{B}=E R U S H$ VOLTAGE DROF ( O.8V PER BRUSH)

$\boldsymbol{R}_{\text {tot }}=S U M$ OF ALL CIRCUIT RESISTANCES

$L_{\text {tof }}=$ SUM OF ALL CIRCUIT INDUCTANCES

Fig. 11 .

$L-C$ energy transfer circuit. $\frac{1}{2} \theta \omega^{2}-\frac{1}{2} \mathrm{Ct}_{0}{ }^{2}$

and its time derivative

$\theta \omega \frac{d \omega^{t}}{d t}=C v_{0} \frac{d v_{0}}{d t}$

which show that the following relationship holds:

$c=\theta\left(\frac{\omega}{v_{0}}\right)^{2}$

$\mathrm{N}$ compression coils are connected in parallel to the same homopolar machine so that the current $I=$ $\mathrm{NI}_{(\mathrm{cul})}$, the coil induct ance $\mathrm{L}_{\mathrm{C}}=1.1 \mathrm{~L}_{\mathrm{Crij}} / \mathrm{N}$, and the coil resistance $\mathrm{R}_{r}=1.1 \mathrm{R}_{\mathrm{coil}} / \mathrm{N}$; the factors 1.1 are to include the leads.

The circuit equation may he written immediately in the Laplace domain, i.e..

$0=\frac{-\Delta V_{B}}{B}+\frac{I(s)}{s C}+\frac{V_{O}}{s}+I(s)\left(R_{\text {tot }}+s L_{\text {tot }}\right)$,

where $s$ is the Laplace operator and where $-J V_{\mathrm{W}} / \mathrm{s}$ and $V_{1} / s$ are the initial value terms. assuming that the initial voltage generated is $V_{O}-J V_{B}$.

The current is thus obtained from inverse transformation of $\mathrm{Eq}$. (27). i.e..

$$
\text { where } \begin{aligned}
I= & \frac{v_{0}-\Delta V_{B}}{\Omega L} e^{-\delta t} \sin \Omega t, \\
\Omega_{0}^{2} & =\Omega_{0}^{2}-\delta^{2}, \\
\delta & =1 /\left(L_{t o t} C\right), \\
& =R_{t o t} /\left(2 L_{t o t}\right) .
\end{aligned}
$$

The maximum current occurs for $\Omega \mathrm{t}=\arctan (\Omega / \delta)$ for which $\mathrm{Eq}$. (28) yields

$$
\begin{aligned}
& I_{\max }=\frac{\nabla_{0}-\Delta V_{B}}{z_{0}} \exp \left[-\frac{\delta}{\Omega} \arctan \left(\frac{\Omega}{S}\right)\right], \\
& \text { where } z_{0}=\sqrt{L / C}
\end{aligned}
$$

The machine voltage $v_{c}(t)=1 / \mathrm{C} j$ idt is now easily obtained, i.e..

$v_{c}=\left(v_{0}-\Delta v_{B}\right)\left(\cos \Omega t-\frac{\delta}{\Omega} \cdot \ln \Omega t\right) e^{-\delta t}$. 
At lime $t=\pi / 9$, we have $i=0$, and from Eq. $(29)$

$\frac{v_{C}(\pi)}{v_{0}}=\frac{\Delta v_{B}}{v_{0}}-\left(1-\frac{\Delta v_{B}}{v_{0}}\right) \exp (-\delta \pi / \Omega 2)$.

The circuit efficiency is given by

$n_{\text {c1rcult }}=\left(\frac{v_{c}^{(\pi)}}{v_{0}}\right)^{2}$

and the loss per half-cycle may be written

$\frac{1}{2}\left(\mathrm{I}-n_{\text {clrcuit }}\right) \mathrm{Cv}_{0}^{2}$.

We later add to this loss the coasting losses. which consist of brush friction loss. bearing loss. refrigeration loss, and charging loss, to yield the total loss per pulse cycle.

\section{B. Machine Topology Considerations}

Figure 12 illust rates the topological configurations that have been considered for fast-discharging homopolar machines. These alternatives are discussed in some detail in this section.

Figure 12a shows the single disk, which is mechanically the simplest configuration. The shaft cau be simply supported in two radial bearings. result ing in the highest natural frequencies of any of the designs. However, it pays for its mechanical simplicity in electrical complexity. To avoid extremely high axial thrusts during discharge. equal currents should be collected from terminals at each end of the machine. Also, the simple disk does not economically lend itself to large installations. because once the practical size limit is reached for a single disk, the entire system must he duplicated.

Anot her drawback of the single disk approach has been discussed in detail previously. ${ }^{+}$Briefly stated, for a given energy requirement. the discharge time is inversely proportional to the equivalent capacitance of the homopolar machine(s). For a given energy storage, multiple rotors are capable of producing higher voltages and thereby lower capacitances and shorter discharge times. This is true because for a given rotor material and operating stress level, the energy stored in the rotor is proportional to the radius cubed. whereas the voltage is directly proportional to the radius.

The final limitation of a single disk machine that should be mentioned is the fact that as discharge times become small and peak decelerating torques consequently become high. the machine structure and foundation must be capable of sustaining the large forces involved.

The counterrotating disk configuration in Fig. $12 \mathrm{~b}$ eliminates this last problem because the net angular momentum of the wo rotors is always constant (zero). In addition the voltage of' such a machine is greater for the same energy, or a machine storing twice the energy (two rotors) (an be built using ay)proximately the same field coil and st ator assembly required by the simple disk. The counterrotating syc.em is also electrically more convenient because all power is available from a single set of terminals. but it is mechanically more complicated because the rotors are cantilevered by the shafts. This tends in lower the natural frequencies of the shatt-roturbearing system and results in the possibility of interference wit h rotational speeds encountered during the operating cycle. Although conveniently doubling the energy available in a single disk system. this sytem still is not suitable for large, mulipple rotor machines necescary for multigigajoule installat ions.

Figure 122r illustrates a logical extension of the configuration shown in Fig. 12h in which the cantilevered rotors of adjacent machines are placed on common shafts. This "spool" configuration does lend itself to multiple rotor installations and also eliminates one set of stiding contacts the shatt brushes) per rotor. thereby providing a decrease in brush losses and a corresponding increase in machine efficiency. Infortunately, the relurn conductor rout ing becomes complex if the machine's internal inductance is to be minimized.

The inside return conductor spool machine, shown in Fig. 12d, significantly simplifies the return conductor configuration at the expense of a slight penall. $t y$ in internal inductance.

Intil now, the discussion of topolongical alternatives for homopolar machines centered aruund disk-type devices, that is, devices using axial magnetic lields and radial current llow. A similar lamily of devices, referred to as drum-type machines, uses radial magnetic lields and axial current flow. The similarities and differences: between disk and drum devices have heen covered in detail in Rof. 4, and the outside and inside roturn conductor equivalents are shown in Fig. l'Le and $f$. The outside return conductor drum machine allows conventional. small-diameter rotor bearings at the expense of increased tlux leakage because tho roturn conductor in this configuration occupies the area of highest flux density. The inside return conductor drum configuration allows greater thux linkage and consequently higher voltage for the same rutor but it requires the development of large-diameter. highspeed bearings for the outside of the drum. However. this seems to be an icleal application for gas bearings, as shown in Sec. I). 


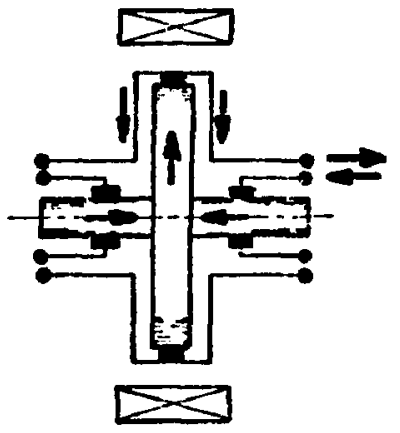

a. SIMPLE DISK

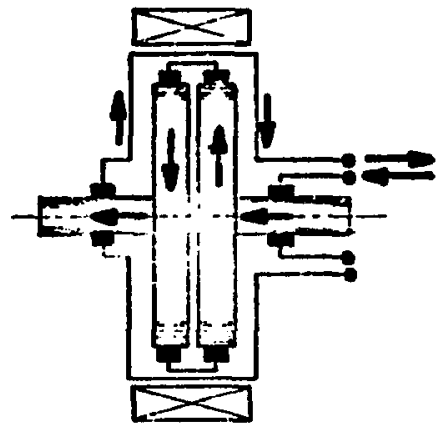

b. COUNTERROTATING DISKS

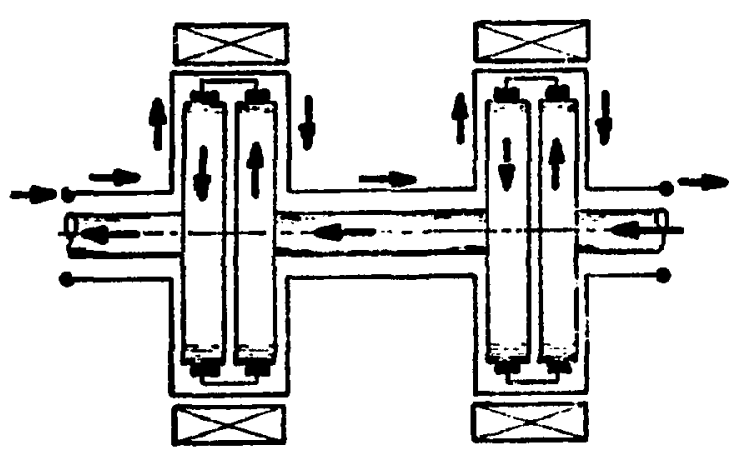

c. SPOOL MACHINE (OUTSIDE RETURN CONDUCTOR)

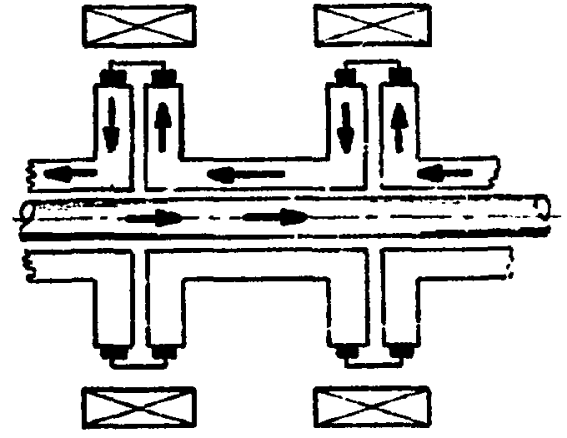

d. SPOOL MACHINE (INSIDE RETURN CONCUCTOF)

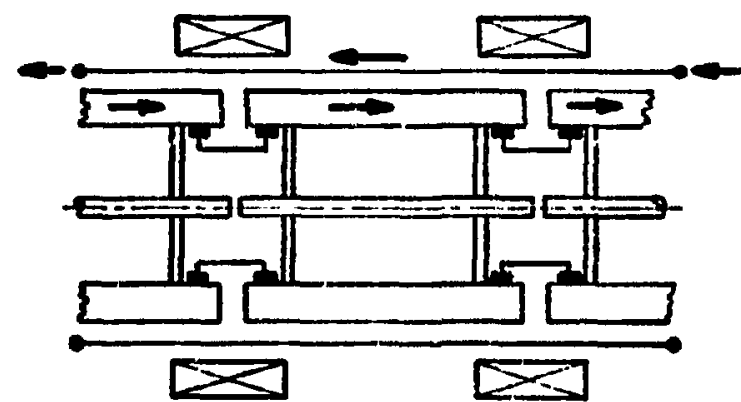

e. URUM MACHINE

(OUTSIDE RETURN CONDUCTOR)

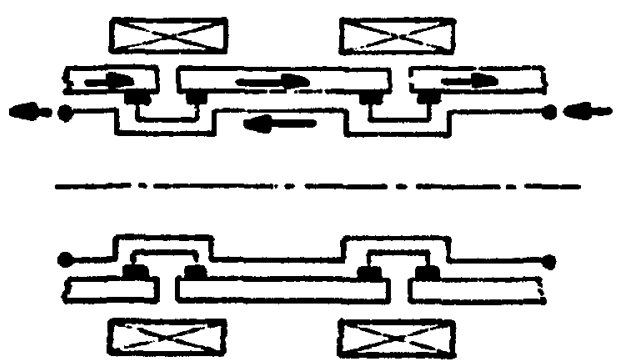

f. DRUM MACHINE (INSIDE RETURN CONOUCTOR)

Fip. 12.

Alternutice topological confinurations for fast-discharging homopolar machines. 
The relative atsintages of the spoul and drum entigurations ean best he stummarized as follows.

-The drum conliguration has the pentential of hwer internal imsedinece and lherefore higher dischargere etfitejency:

-The disk and speol sonligurat ions h:sse alo ponelltial for maximum thux linkage anai therefoue hjgher

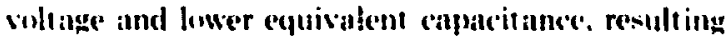
in lower potential disitharge times for the spund entfigurat ioms.

\section{Rotor Mechanical Considerations}

The two types of homopolar machine (on) tigurations. Ile disk and drum ivpes. are again shown in Fig. 1:3.

1. Disk Machine. The disk configuration was successfully designed. built. and tested at the I niversily of Texas at Austin. The configuration is mechanically simple. consisting essentially' of a disk that is shrunk fit onto a solid shalt.

When conceptual applications began requiring more than one disk. and particularly in fusion studies where losses are critical. the spond design emergerl 1Fig. 14!.

Becouse a hole in the shaft lor an internal return conductor would be required in our dlesign. the effect of the hole on the fatigue life of the machine must be considered.

Lo't us assume that a dlisk and a solid shaft are to be shrunk fit toget her and spun with angular velocitv u. The maximum tangential stress at the inner surtace of the disk is

$$
\sigma_{t}=\frac{Q \omega^{2}}{B}\left[(3+\mu) c^{2}-(1+3 \mu) b^{2}\right]+\frac{E \delta_{1 n}}{2}\left(1+\frac{b^{2}}{c^{2}}\right)
$$

$$
\begin{aligned}
& w^{\prime} \text { ere } \mu=\text { Poisson's ratio for the material } \\
& p=\text { density of material } \\
& c=\text { outer radius of disk } \\
& \text { b = inner radius of disk } \\
& a=\text { inner radius of shaft } \\
& p_{c}=\text { Young"s modulus of elasticity } \\
& \delta_{i 11}=\text { initial shrink fit interlerence per unit }
\end{aligned}
$$

If a hole is put in the center of the shatt, the tanuential stress al the inner radius of the disk becomes

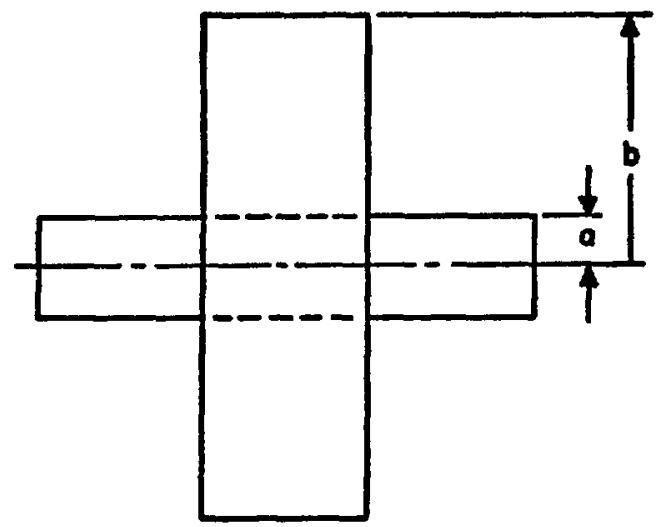

DISK TYPE

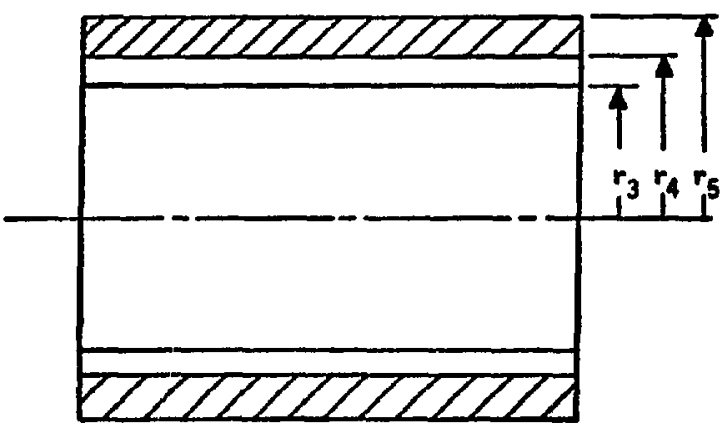

DRUM TYPE

Fig. 13.

Disk shrunk on shaft and composite reinforced drum.

$$
\begin{aligned}
\sigma_{t} & =\frac{\rho \omega^{2}}{4}(3+\mu) c^{2}\left[\frac{1}{2}+\frac{b^{2}}{c^{2}}\left(\frac{1-\mu}{3+\mu}-\frac{1}{2}\right)+\frac{a^{2}}{2}\left(\frac{1}{b^{2}}+\frac{1}{c^{2}}\right)\right] \\
+ & \frac{\mathbb{E C} \ln }{2} \frac{\left(b^{2}-a^{2}\right)\left(c^{2}+b^{2}\right)}{b^{2}\left(c^{2}-a^{2}\right)}
\end{aligned}
$$

The maximum alternating stress

$$
\sigma_{a 1 t}=\sigma_{t}\left(\omega=\omega_{\max }\right)-\sigma_{t}(\omega-0)
$$




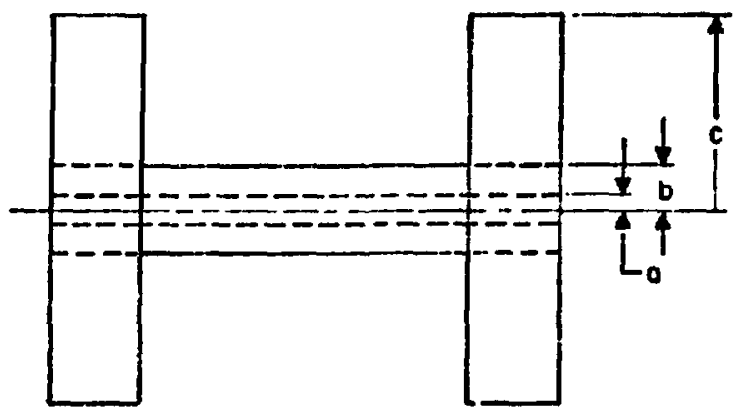

SPOOL TYPE

Fig. 14.

Spool consisting of dishs shrunk on hollow shaft.

is less if Ey. (31) is subst it uted in Ey. (33), than with Ey. (32) substituted. This indicates that the fat igue life of the hollow shaft design is inferior to that with solid shaft. Therefore, the speed must be reduced if a hollow shaft is used. This is to be expected because any hole, regardless of size, prevents a radial restraining force between two points $180^{\circ}$ apart on its periphery.

2. Drum Machine. Consider two concentric drums, one the rotor material and the other the composite wrap (Fig. 13b), rotating at some angular velocity $\omega$. Assume that the composite is not pretensioned. Fach material tries $10 \mathrm{grow}$ radially out ward due to centrifugal force. However. the amounts of griwth differ because of the materials" different stiffnesses. The composite is much stiffer and stronger than the rotor material. Therefore. the rotor material tries to grow more than the composite and is thus constrained by the composite by all apparent interierence

$$
\begin{aligned}
J & =U_{c}-U_{r} \text { (at interface radius) } \\
\Delta & =\frac{\omega^{2}}{4}\left\{\frac{D_{c}}{E_{c}}\left[\left(3+\mu_{c}\right) r_{s}^{2}+\left(1-\mu_{c}\right) z_{4}^{2}\right]\right. \\
& \left.-\frac{D_{r}}{E_{r}}\left[\left(3+\mu_{r}\right) r_{s}^{2}+\left(1-\mu_{z}\right) r_{L}^{2}\right]\right\},
\end{aligned}
$$

where $\Delta=$ apparent interference per radius unit

$$
\vec{U}_{c}=\begin{gathered}
\text { radial growth of composite per radius } \\
\text { unit }
\end{gathered}
$$

$$
\begin{aligned}
& l_{r}=\text { radial growth of rotor material per } \\
& \text { radius uni1 } \\
& m_{1}=\text { density of comprsite } \\
& \mathrm{m}_{\mathrm{f}}=\text { density of rotor material } \\
& \mathrm{F}_{4} \text { = Young's Modulus of Elasticity of } \\
& \text { composite } \\
& F_{q}=\text { Young's Modulus of Elasticity of rotor } \\
& \text { matcrial } \\
& \mu_{1}=\text { Poissoll's ratio of composite } \\
& \mu_{r}=\text { Poisson's ration of rotor material }
\end{aligned}
$$

This apparent interference causes an interface pressure. P.

$$
P=-\frac{\Delta}{\frac{1}{E_{c}}\left(\frac{r^{2}+r_{s}^{2}}{r_{s}^{2}-r^{2}}+\mu_{c}\right)+\frac{1}{E_{r}}\left(\frac{r^{2}+r^{2}}{r^{2}-r^{2}}-u_{r}\right)} \text {. }
$$

Vote that $J$ will be a negative value because the rotor material tries to grow more thon the composite.

With $\mathrm{P}$ determined. one can then determine the stresses. The largest st ress for each material will be at its respective inner radius and san be calculated using the following equations:

$$
\sigma_{t, t \text { iil }}=\sigma_{\text {, pin }} \pm \sigma_{\text {promart }}
$$

$\sigma_{1,}=$ tangential stress of rotor material at inner radius $r_{3}$

$$
\begin{aligned}
& \sigma_{t r}=o_{r} \omega^{2} \frac{3+u_{r}}{8}\left[2 r^{2}+r_{3}^{2}\left(1-\frac{1+3 u_{r}}{3+u_{r}}\right)\right] \\
& -2 P \frac{r^{2}}{r^{2}-r^{2}}
\end{aligned}
$$

$\sigma_{t c}=$ tangential stress of the composite at inner radius $r_{4}$

$$
\begin{aligned}
& \sigma_{t c}=\rho_{c} \omega^{2} \frac{3+\mu_{c}}{8}\left[2 r_{s}^{2}+r^{2}\left(1-\frac{1+3 \omega_{c}}{3+t_{c}}\right)\right] \\
& +P \frac{\tau^{2}+\tau_{4}^{1}}{r_{s}^{2}-r^{2}} .
\end{aligned}
$$

Using the following values and previously stated equations. we calculated the maximum tangential stresses for the composite and rolor inaterial. 
Rutor material - aluminum (6)(3)3-T(i)

$$
\begin{aligned}
& \mu_{r}=2.71 \times 10^{3} \mathrm{~kg} / \mathrm{m}^{3} \\
& F_{r}=7.58 \times 10^{10} \mathrm{~N} / \mathrm{m}^{2} \\
& \mu_{r}=0.38
\end{aligned}
$$

Composite-graphite libers in an epxxy matrix (Celion $\mathrm{GY}: \mathrm{T}(\mathrm{)})$

$$
\begin{aligned}
& \mu_{c}=1.66 \times 10^{33} \mathrm{~kg} / \mathrm{m}^{3} \\
& F_{4}=28.93 \times 10^{10} \mathrm{~N} / \mathrm{m}^{2} \\
& \mu_{c}=0.25 \\
& r_{i}=0.967 \mathrm{~m} \\
& r_{1}=0.970 \mathrm{~m} \\
& r_{i}=0.973 \mathrm{~m} \\
& \omega^{\prime}=264 \mathrm{rad} / \mathrm{s} \\
& د=-1.9573 \times 10^{-3} \\
& P=3.870 \times 10^{5} \mathrm{~N} / \mathrm{m}^{2} \\
& \sigma_{i r}=6.180 \times 10^{-1} \mathrm{~N} / \mathrm{m}^{2} \\
& \sigma_{1 c}=2.347 \times 10^{8} \mathrm{~N} / \mathrm{m}^{2}
\end{aligned}
$$

These stresses are well under the allowable stresses for each material for a 25.yr life, based on Goodman diayrams.

To account for the electrodynamic forces, we let $I_{1}$ he the current through the inner ret urn conductor. l. be the outer ret urn current, and $i_{11}=I_{1}+I_{\text {.2 }}$ be the rotor current. The corresponding tield energy

$W=\frac{1}{2}\left[\left(L_{12}+L_{23}\right) I_{1}^{2}+L_{34} I_{0}^{2}+\left(L_{460}+L_{65}\right) I_{2}^{2}\right]$.

where the inductances were defined in Fys. 114) and |liil. 'The radial electrulynanic pressure on the drum

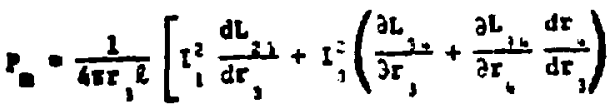

$$
\begin{aligned}
& \left.+I_{2}^{2} \frac{\partial t}{\partial t}=\frac{d r}{d t}\right]
\end{aligned}
$$

where the derisntives of 1.12 and $l_{\text {.tit }}$ vanished hwonse of their $r_{b}$-independence and whore

$$
\frac{d x_{4}}{d x_{3}}=1-2 \mu \frac{r_{4}-r_{2}}{(1+\mu) x_{4}+(1-\mu) r_{4}}
$$

The tangential stress restling from the internal makmulic prossute $\sigma_{\text {magnet Ic }}-P_{a}\left(r_{4}^{2}+r_{3}^{2}\right) \mid\left(r_{4}^{2}-r_{3}^{2}\right)$

Remembering that the spin stress is proportional to $\omega^{2}$ and the magnetic stress to $i^{2}$. we recall the relationships Eys, (26) and (28). Neglecting the exponential term in . Fq. (28), we write for the com. bined st ress:

$$
\sigma=\sigma_{\text {spin }}-\left(\sigma_{\text {iprin }}-\sigma_{\text {matznetie }}\right) \sin ^{2} \Omega \mathrm{t}
$$

The current returned via the outer return conductor. i.e., the ratio $I_{1} I_{\text {, }}$ is chosen so $\sigma_{s, j i n}-\tau_{\text {magnetir }}>0$. The desired current ratio is easily achieved in practice by. conrecting the pruper number of coils to the outer return conductur. and the rest to the inner ome.

\section{Gas Bearing System}

A gas hearing is suited for designs involving high relative velocities and light loads typical in the l.-C circuit applications discussed in this report. In the case of the 1,025-m-radius rotor listed in Table I, for example. the mass of the rotor is only $41 ; \mathrm{kg}$. The bearing pressure from this gravity load is $875 \mathrm{~N} / \mathrm{m}^{2}$ (0.13 psi). At a loading this light, the rotor could actually slide in the bearing. with no lubricant. to a siguilicant speed without excessive wear."

Following is a list of the assumptions used in calculating the loss due to the radial hearings and a short discussion of' the errors involved in their use.

a. Braring Type. A hydrodymamic gas hearing* is well suited for this application. However, we assume a cuarter station film-compensated hydrostatic gils hearing, as shown in Fig. 15. In this bearing. pressurized gas is pumped through orifices into the clearance between the bearing and rolor. The r(aisin) for this bearing choice is its advantage of greater llexilility in avoiding critical frecuency problems wer that typical for hydrodynamic bearings. During detailed design. the hydrodymamic bearing should not. however, bo disregnrded. bo'muse its much lower loss is attractive. In other words, tho gualuter station lilm-compensated bearing was chesen becouse it is the most comsersative in torns of stability anel lesis.

b. Broring Clearaner. The bearing clearan ese is

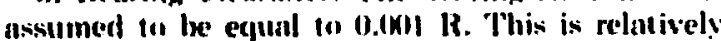
large for a gas levaring and may have fo lo reduced for stubiliry rensms. As we will show Intor, the loenting lissces are dominnted to the compressis puser. Thus. ans reduction in the ctearances will tond (1)

*A hudrod vamic bearing achicuess pressurizatien by sponnins. 


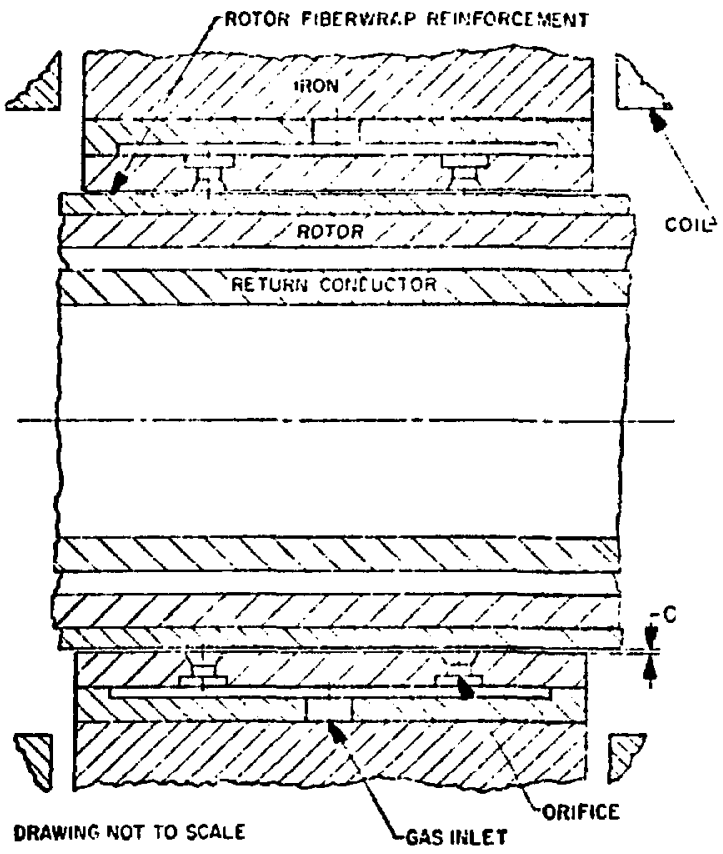

Fig. 15.

Quarter station, film-compensated gas bearing.

reduce the bearing loss due 10 the result ing reduction in gas flow. The main reasons for choosing such a large clearance are assembly consideration and rotor growth. where the latter is on the same order as the hearing clearance. The clearance at rest and zero current is obviously larger than the operating clearance. In other words, a large clearance is desirable to reduce the relative mannitude of the spin and electrodvnamic rotor growths.

$r$ (igs. The gas is assumed to be hudrogen at an ambient pressure of $1 \mathrm{~atm}$. Becrause of cosling comsiderations, this pressure must be increased. however. This results in a decreased kinematic viscosity. making operation in the laminar regione imposible for the given range in clearance.

d. Flow Regime. Our calculat ions lor laminar gas llow in the bearing were carried out for two reasons. (II) Initial evaluation of turbulent flow indicates significant reduction in compressor power accom. manied lov an increase in drag on the rotur. Bucause hearing luss is dominated by compressor pumping pewer. a net reduction in bearing loss may result for lurhulout amalysis as compared with laminar flow analssis. 12, The bearing with I alm hydrugen "Ixorutces in the laminar thow regime. and the calculations for it are simple. wherens mumerical evaluation of the turbulent hydrostatic bearing complicates parameter space mapping.

Following is the algorithm used in calculating the loss astociated with the quarter station laminar flow system. The equations cited are used in the design program DRUMTYP described in Sec. IV.

The tirst step is to calculate the required bearing stiffiness $K_{t}$ to insure that the first bearing-rotor critical speed is above $\sqrt{1.5}$ times the operating speed. i.e..

$$
K_{\mathrm{b}}=1.5 \omega^{2} \mathrm{~m}
$$

where $\mathrm{m}$ is the rotor mass.

Next, the difference between the supply pressure $P$, and the ambient pressure inside the machine $P_{H}$ is calculated using the equation "

$$
x_{b}=\frac{C_{L} D_{L_{B}}\left(P_{B}-P_{a}\right)}{0.5 c} \text {, }
$$

$$
\text { where } \begin{aligned}
C_{l} & =\text { load coefficient }=0.17 . \\
D & =\text { bearing diameter, and } \\
I_{+3} & =\text { bearing length. }
\end{aligned}
$$

Next, the gas mass flow rate $G$ required to maintain this pressure drop is calculated using

$$
\text { G. } \frac{\pi R C^{3}\left(P_{1}^{2}-P_{2}^{2}\right)}{6 \mu L_{2} R T}
$$

where $P_{1}=$ bearing pocket pressure $=P_{s}+P_{A} / 2$

$$
\begin{aligned}
& \mu=\text { gas viscosity }=1 \times 10^{-5} \mathrm{Nsm}^{\cdot 2} \text { for } \mathrm{H}_{2} \\
& L_{2}=L_{H} / 4 \\
& \bar{R}=\text { gas const ant }=4121 \mathrm{~J} \mathrm{~kg}^{-1} \mathrm{~K}^{-1} \text {. and } \\
& \mathrm{T}=\text { ambient temperat ure }=34: 3 \mathrm{~K} \text {. }
\end{aligned}
$$

The compressur power $H$ to supply the gas can now be calculated using"

a $=\frac{G+2 k}{(k-1)^{n}}\left[\left(\frac{P_{2}}{P_{2}}\right)^{\frac{k-1}{k}}-1\right]$,

where $k=$ ratio of specific heats $=1.4$

$\eta=$ compressor efficiency $\approx 0,8 ;$.

The laminar shear loss $H$, for the bearing can now be calculated using:"

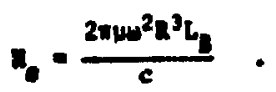

Applying turbulent theory : 10 this conse predicts an incrense in drag by a factor of alkut 3. 
The total loss for the bearings without considering the benefits of turbulence on the compressor loss varies between 42 and $95 \mathrm{~kW}$ time-averaged over th. 0.4-s pulse period, or $0.21-0.4 \sigma^{\prime}$, of the energy stored initially for the examples listed in Tables 1 and II of Sec. IV.

The major effects of discharge on the rotor-bearing system occur in two areas: gas dvnamics in the bearing and electrodynamic forces on the rotor due to deviations from ideal symmetry in the actual design. The gas dynamics problem is related to the turbulence induced by the sudden starting and stopping of the cylinder. Because the flow regime is turbulent during steady state. this additional turbulence is not considered significant. The elec. trodynamic forces on the rotor are due to deviations from the ideal, perfectly aligned case because they originate from misalignment of the electrical and mechanical axes and from uneven current distribu. tion in the rotor. The study of these phenomena has begun at the University of Texas at Austin . Initial calculations show that these forces do not cause failure of the $1.025-\mathrm{m}$ rotor radius reference machine, partly because of the rotor displacements that can be tolerated in the gas bearing. Axial (thrust) gas bearings of conventional design to withs' and axial forces generated from misalignment can be used. In this case the bearing loss is dominated by the radial bearing.

\section{E. Current Collecting Brushes}

The sliding elect rical contacts and their actuating mechanism will require further development. The operating conditions described here are based on data collected by the Energy Stornge Group at the University of Texas at Austin8 At speeds from 80 to $170 \mathrm{~m} / \mathrm{s}$ and a current density of $6.7 \mathrm{~A} / \mathrm{mm}^{2}$. coefficients of friction from 0.15 to over 0.35 were measured. Their 5-M.J homopolar machine generates $0.7-\mathrm{s}, 560 \mathrm{kA}$ pulses with brush current densities of $24.9 \mathrm{~A} / \mathrm{mm}^{2}$. Data were collected using sintered copper-graphite hrushes sliding on AISI $4: 340$ steel slip rings.

Controlled atmosphere tests are now being run to investigate the performance of similar hrushes on specially coated aluminum alloy slip rings. We expect preliminary results by mid 1976.

Becruse of the numerus pulses required in this application, the high repetition rate. and the very hip! I $\times B$ forces in the brush area, conventional sliding hrush mechanisms are unacceptable. The brushes must be raised between discharyes because of the brush and rotor henting considerations, the officiency. and brush wear requirements. The hrushes can be mounted on cantilevered beams, which sirve as current carrying and brush locating functions (Fig. 16i. The University of Texas 5-M.l homopular machine uses similar beams, which delhect elustically to raise and lower the brushes and plasticially in compensate for wear. Such devices an wilhstind large o $\times \mathrm{B}$ forces and still require low actuation force. They also are susceptible to fatigue from the numerous cycles anticipated lassuming 1-yr hrush life). but they are easily replaced in units with the brushes.

This suggests the possibility of using individual brushes polymerically bonded into circumferential rings (Fig. 16h). The brush rings conld then be deflected onto the slip rings by an actuating fluid. and the polymer could supply the restoring spring force. The direct action of the fluid on the lrushes: and the required brush system response suggest that acoustic shock waves or a resonant thidic system be used to control the up-down cycle of the hrushes. Work is under way at the Iniversity of 'Texals on systems using this principle.

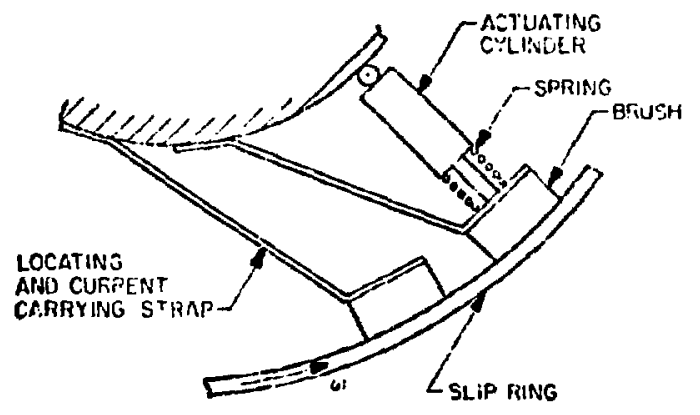

a. CANTILEyeR

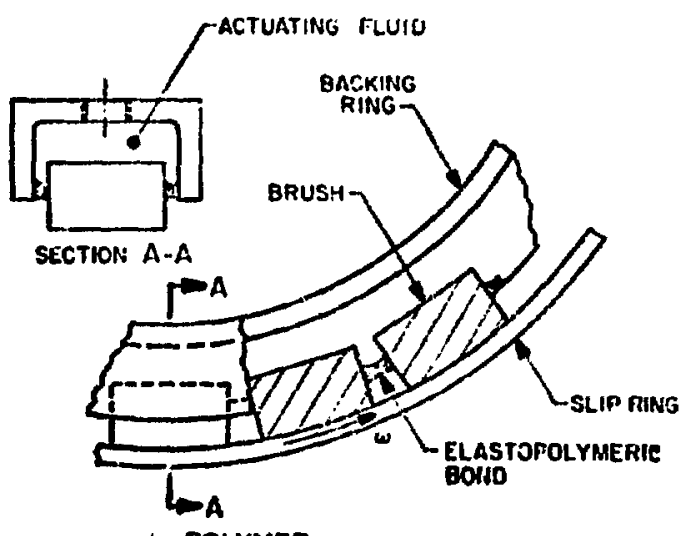

b. POLYMER

Fis. 16.

Current collectins brush mechanism. 
It is assumed in the optimization computations that the brush contact load averaged over the $0.4-5$ pulse cycle is 4.5 mbar. For the $\sigma_{1}:=3 \mathrm{~ms}$ case, this is equivalent to a static load of 1 bar over a 9-ms intersial during which the brushes are lowered to contart with the drum. plus an electrodynamic brush load $\left(\propto i^{-2}\right)$ with $*$ bar crest. The friction coefficient is assumed to be 0.22 as shown in Table 11 of Sec. IN. and the brush volt ane drop is assumed $\mathrm{JV}_{\mathrm{B}}=0.8 \mathrm{~V}$ per hrush.

\section{F. Thermal Considerations}

Most of the joule losses occur in the rotor during emergy t ransfer to and from the machine. Additional lusies are caused hy friction and contact resistance at the brush-rotor interlaces. The joule heating is unilorm in the aluminum conductor of the rotor. On the inner surface at buth ends of the rotor, a surface heat hux will occur because of t he contact resistance and frictional heating of the brushes.

In the logitm inotor discussed in Siec. IN, the rutur choling strstem must remose $1.6 \mathrm{MW}$. $15.4 \mathrm{x} 10^{6}$

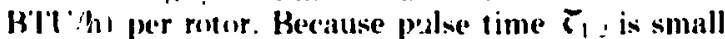
cumpared with the 0.4-s pulse eycle. the generated hoat alpears primarily in the rotor and will be evichelleed by a rise in temperature. Most of the active cowling must then be essentially accomplished betweren pulses Assuming the aluminum conductor material woighs: $350 \mathrm{~kg}(\mathrm{~s}, \mathrm{f}(\mathrm{C} / \mathrm{h})$ and the specific heat is $879 . \mathrm{Jkg} \cdot \mathrm{K}^{-1}\left(0.21 \mathrm{BTU} / \mathrm{hb}{ }^{\circ} \mathrm{F}\right)$, we find that for a single pulse the temperature rise is $2^{\circ} \mathrm{C}\left(33^{\circ} \mathrm{F}\right)$. This periodic rise in temperalure coincides with the transfer of encergy from the machine and is superimpused on the - weady-stalle operating temperature of

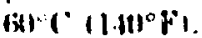

The alluminum condercor is surroumded by a com posite of graphite fileers in an epoxy matrix. The rotor spins in an anmular spate formed by the gas lo:iring and tiold coijls on the out side and the ret urn conductor on the inside. Comiling cleceric generators hy thowing hudrogen gals axially in the annular gap lot ween stationary and rotalting parts is crommon. Asisuming that the houncuphlar machine is couled hy hydrogen gais, all cexpressionl fur the st eady-stnte heot remoxill eall loe wrillen

$$
\begin{aligned}
& \dot{q}_{I}=\dot{i}_{I} c_{p} \Delta T_{L}+v_{I} A_{l}\left(T_{R}-T_{C}\right) \\
& +\dot{B}_{0} c_{p} \Delta T_{80}+y_{0} A_{0}\left(T_{k}-*_{p}\right)
\end{aligned}
$$

\footnotetext{
where

$b_{1}=$ msornge hem rate

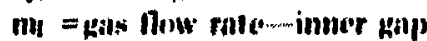

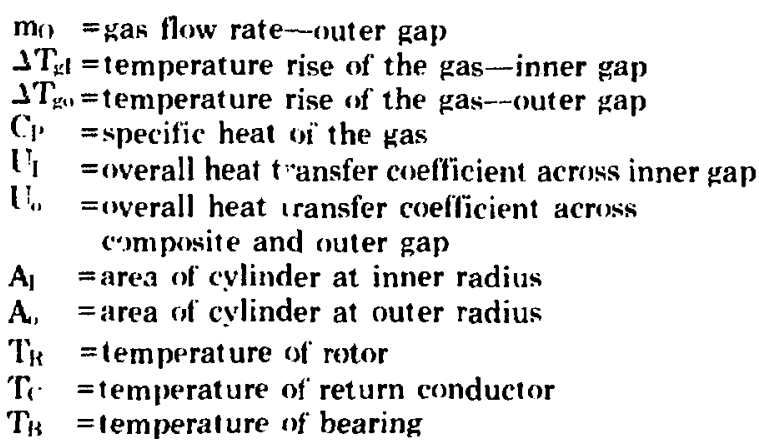

Equation (38) requires that the average heat generation rate equal the heat rate that can be transferred to the hydrogen gats flowing in the inner gap and across that gap to the return conductor. It also includes heat transferred to the hydrogen gas used by the bearing (in the outer gapl and across that gap to the bearing surface. The heat removed across the gap is assumed to be removed by a higher density nluid.

Heat transfer coefficients for flow modes encountered with axial flow between rotating concentric cylinders is nut well described in the literature for the inner gap of the proposed configuration. However. heat transfer estimates can be obtained from Kays and Leung" for axial flow between stationary walls; these heat transfer rates would be considered conservative for our configuration because the swirling flow induced by rotation lends to improve heat transfer. For the outer gap. Becker and kaye" "have reported data for diabatic flow:* however. our caste dues not fall in the range of their dilla for axial flow. Therefore. a zero axial how correlation was used for our estimates.

Operation of the gas hearing requires $y$ hydrogen gas flow of $(\mathrm{s}(\mathrm{O}) \mathrm{kg} / \mathrm{h}(1: 3,50 \mathrm{lb} / \mathrm{h})$. This flow offers advantinges for heat removal by means of its heit

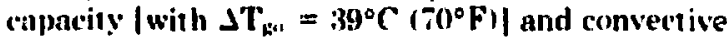
(ransfer to the bearing surface (cos)led to an ambient tomperature of $\left.10^{\circ} \mathrm{C}(30)^{\circ} \mathrm{F}\right) 1$. These advantages would be significant in that 201, of the total heat generated wrould be removed. The remaising heat remenval would require $-54(0) \mathrm{kg} / \mathrm{h}(120(0) \mathrm{lb} / \mathrm{h})$ of hydrogen with ${ }^{\prime} \mathrm{T}_{\mathrm{Rl}}=39^{\circ} \mathrm{C}$ at $5 \mathrm{~atm}$. Active cooling of the gons bearing and return conductor would require $31 \mathrm{~m}^{3} / \mathrm{h}(225 \mathrm{gpm})$ of water at $د \mathrm{~T}_{*}=11^{\circ} \mathrm{C}$ $\left.(2)^{\circ} F^{\prime}\right)$. We believe that careful evaluation of wuch effects as rotor surface roughnesis. unstendy motion of the rotor, and swirling flows would lower the requirud hydrogen flow rate and operating pressure. In such a case nure heat would be transferred across the galp: however, a higher water flow rate would alsos

- Diabatic is synomymus to nonadiabatic. 
be necessary. These tlow rate estimates for cooling suggest that care must be exercised in designing such a system.

\section{G. Cost Equations}

The conceptual design work for the Reference Theta-Pinch Reactor (RTPR) is under contract with the Electric Power Research Institute (EPRI). ${ }^{i 1}$ Costing of the 1.3-G.J, 60-ms discharge machine for the (RTPR) is done with the following cost formula.

$\$_{\text {tot }}=1.2 \mathrm{n}\left(M_{\mathrm{Fe}} \$_{\mathrm{Se}}+M_{S C} \$_{S C}+M_{C} \$_{C}+A_{B} \$_{B}\right),(33)$

where $\mathrm{M}_{\mathrm{F} \cdot}=$ iron weight copper

$\mathrm{M}_{\mathrm{sc}}$ = supereonductor weight including

$\mathbf{M}_{\mathbf{C}} \quad$ = weight of drum conductors and return conductors

$A_{B}=$ brush-to-collector contact area .

The coefticients in the cost equation are

$$
\begin{aligned}
& \$_{\mathrm{Fe}}=1.59 \$ / \mathrm{kg} \\
& \$_{\mathrm{SC}}=63.8 \$ / \mathrm{kg} \\
& \$_{\mathrm{C}}=9.10 \$ / \mathrm{kg} \\
& \$_{\mathrm{B}}=4.81 \$ / \mathrm{cm}^{2} .
\end{aligned}
$$

The set of constants, Eq. (40), has been derived on the premise of large production quantities with considerable cost reduction from learning curves, assuming that three RTPR reactors each with fifty 1.3-G.J homopolar machines have already been com. pleted.

For our purpose. we do not consider large production quantities or small laboratory quantities, and the following cost formula appears to be realistic.

$$
\begin{aligned}
& \$_{t o t}=1.2\left[n K_{F_{e}} s_{F_{e}}+n M_{C} \$_{C}+\operatorname{tnA} A_{B} \$_{B}\right.
\end{aligned}
$$

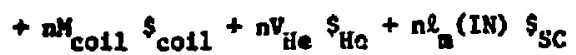

$$
\begin{aligned}
& \left.+\left(\mathrm{uP}_{\mathrm{ref}}\right)^{1+2} s_{\mathrm{ref}}+a \lambda^{2} s_{\mathrm{dewar}}\right] \text {. }
\end{aligned}
$$

where $\mathrm{M}_{\mathrm{Fc}}=$ iron weight Mc = weight of drums and return conductors

$$
A_{H}=\text { brush-to-collector contact area }
$$$$
\mathbf{M}_{\text {coil }}=\text { weight of stabilized }
$$
superconductor (j.e. $0.4 ; \mathrm{coil}$ volume $\times 8.9 \mathrm{~g} / \mathrm{cm}^{3}$ )

$$
V_{H^{*}}=\text { volume of liquid helium inventory }
$$

(i.e. $0.6 \times$ coil volume)

$$
\begin{aligned}
& \text { (JN) = excitation ampere-turns } \\
& t_{r} \quad=\text { mean turn length } \\
& \mathbf{P}_{\text {ref }}=\text { refrigeration power } \\
& \lambda=\text { scaling factor } \\
& S_{\mathrm{Fe}}=1.59 \mathrm{~S} / \mathrm{kg} \\
& 8 \mathrm{c}=9.0 \$ / \mathrm{kg} \\
& S_{\mathrm{B}}=4.80 \mathrm{\$} / \mathrm{cm}^{2} \\
& \$ \text { rvil }=17.5 \$ / \mathrm{kg} \\
& \$_{\text {He }}=2.0 \$ / 1 \\
& \$ \mathrm{sic}=0.00165 \mathrm{~s}^{-1} \mathrm{~m}^{-1}(0.5 \mathrm{mills} / \mathrm{A}-\mathrm{ft}) \\
& S_{\text {ref }}=8400 \$ \mathrm{~kW}^{-0.7} \\
& \$ \text { drwar }=8400 \$
\end{aligned}
$$

The factor 1.2 in Eq. (41) accounts for the assembly cost, which should be 1.25 in those cases where double compensation is required. Cost computed for a machine designed for the LTPHR using Eq. (41) is usually 1.23-1.31 times that obtained trom Eq. (39) with the constants, Eq. (40).

The refrigeration power is given ${ }^{12}$

$$
\begin{aligned}
& P_{\text {refr }}=\left(\frac{T_{\text {op }}}{4.0}-1\right) \frac{P_{\text {loss }}}{n_{\text {compr }}} \text {, } \\
& \text { where } T_{(o)}=\text { operating ambient machine } \\
& \text { temperature } \approx 35.3 \mathrm{~K} \\
& P_{\text {linsi }}=P_{\text {surface }}+P_{\text {leadi }}+P_{\text {rel }} \\
& P_{\text {surfice }}=p\left(T_{\text {up }}-4.0\right) \cdot \mathrm{S} \\
& \mathrm{p}=1.25 \mathrm{~m} \mathrm{~W} \mathrm{~K}-1 \mathrm{~m}^{-2} \\
& \mathrm{~S}=\text { dewar surface } \\
& P_{\text {lesd }}=0.25 \mathrm{~W} \text { (lead loss) } \\
& P_{\text {rel }}=0.1 \mathrm{~W} \text { (relief valve loss) }
\end{aligned}
$$

\section{OPTIMIZATION}

DRUMTYP is a FORTRAN program that maps the parameter space for L-C-R circuits with the homopolar machine and carries out point design. Figure 17 shows a simplified flow diagram of DRUMTYP.

When mapping the parameter space, the following quantities are used.

Constants-Compression coil $\mathrm{L}_{\text {criil }}, \mathrm{R}_{\text {coil }}, \mathrm{I}_{\text {coil }}$

Parameters- $N=$ number of compression coils connected in parallel

$$
\begin{aligned}
& n=\text { number of rotors connected in series } \\
& r_{1}=\text { rotor radius } \\
& t_{12}=\pi / \Omega 2
\end{aligned}
$$

Independent variables $-t_{d r u m}=$ drum conductor thickness

$$
v=w r_{3}=\text { drum surface speed }
$$




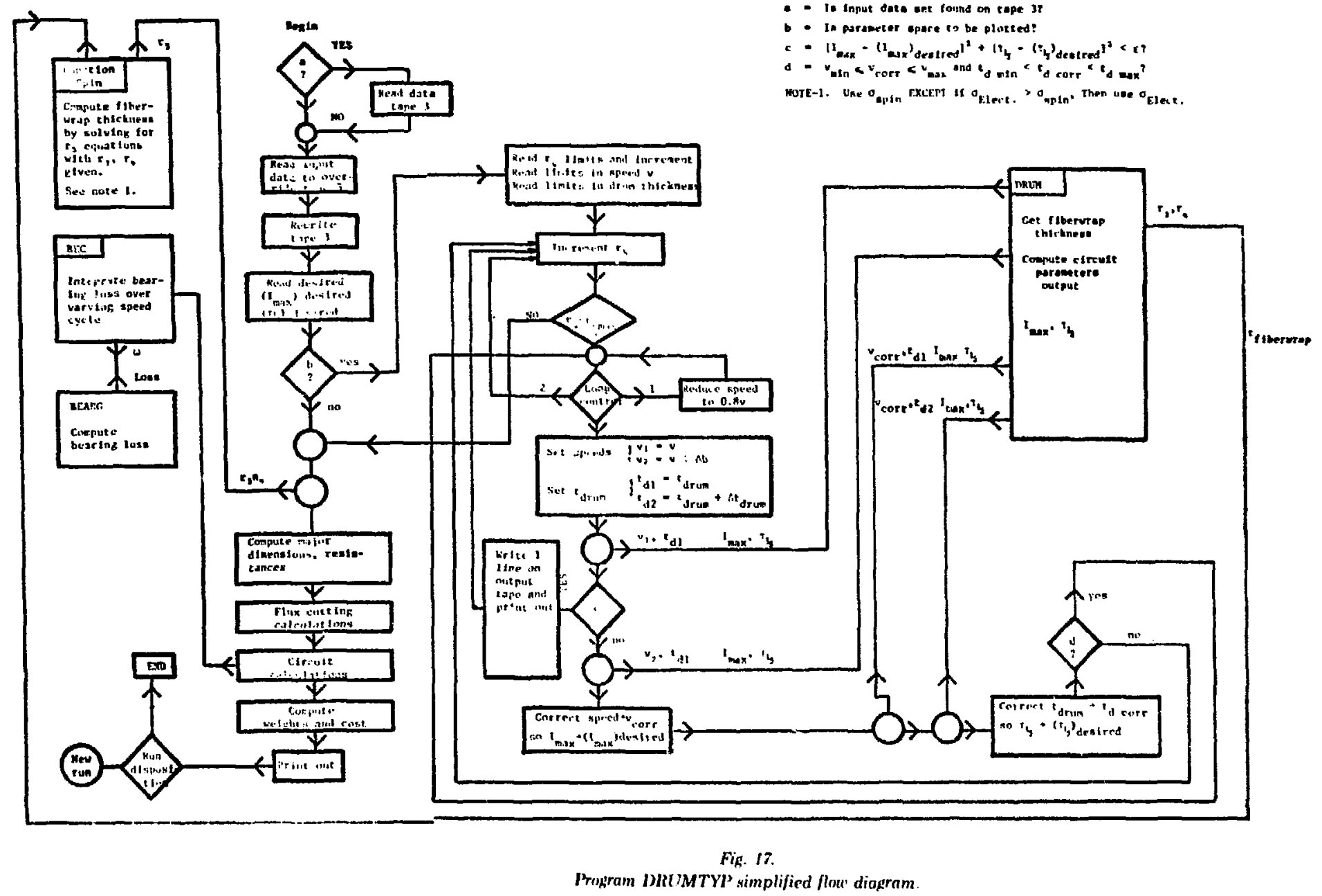


Dependent variables $-\eta=1-f_{1}, f_{e x}+f_{b l k}=$ efficiency

$$
c=100 s_{1, n} / 1 / 2 C_{11}{ }^{2}=\text { cost rate }(d / s)
$$

Figure 18 is a plot of $\eta$ vs $c$ for $N=32.36$, and 40 $r_{1.2}=3 \mathrm{~ms}$, where the parameter $\mathrm{n}=32$ and 36 . The plot shows that efficiency and cost rate increase with increasing radius.

The curves in Fig. 18 move up and to the left. indicating decreasing cost and increasing efficiency with increasing number of rotors (for a given number of parallel (oils) to an optimum beyond which the trend reverses. Hence, with each $N$, there is assiniated an optimum $n$. and for this set of $L$ coil

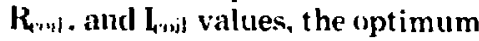

$n_{n, \mu r} \approx N$.

The figure shows that a substantial number of coils must he paralleled for short discharge times, which may result in large currents requiring double compensation.

A useful optimization procedure is therefore as follows. for given $r_{1}: 2$.

(1) Guess initial $\mathrm{N}$.

(ㄹ) Ciuess initial $n$.

(3) licrease $n$; if the $\eta$ vs c characteristic improves, cont inue: if not, decrease $n$; continue until optimum $n_{1,1}$ is forund.

(1) Change $\mathrm{N}$ to $\mathrm{N}=\mathrm{n}_{1 \mathrm{p} t}$, and verify that $\mathrm{n}_{0 \mathrm{p}}$ is still the same, or go back to 3 .

With each $\tau_{1,2}$ value a set (N.n) is associated where $\mathrm{N} \approx n=n_{\text {ips }}$ exists. This optimum chararteristic fits within an error $\mid \pm \epsilon \|<0.5^{\prime}{ }^{\prime} i$ and, neglerting the $4^{\prime} ;$ cost increase discussed in Sec. G. for double crompensition, we find the following equation empirically

$$
n=H_{0}\left[1-\exp \left(-c_{0} / K_{0}\right)\right] \text {. }
$$

The parameters $H_{1}$ and $K_{0}$ in Eq. (4:3) have been plotted in Fig. 19. The variable $c$ is constrained to

$1.510 .3 .5<c / K_{11}<\sim 1.9$ to $15 \begin{cases}1.9 \text { for } \tau_{1 / 2}=1.5 \mathrm{~ms} \\ 3 & \text { for } \tau_{1 / 2}=2.0 \mathrm{~ms} \\ 5 & \text { for } \tau_{1 / 2}=3.0 \mathrm{~ms} \\ 6 & \text { for } \tau_{1 / 2}=5.0 \mathrm{~ms} \\ 9 & \text { for } \tau_{1 / 2}=10.0 \mathrm{~ms} \\ 13 & \text { for } \tau_{1 / 2}=30.0 \mathrm{~ms}\end{cases}$

where the upper limit is set by the flux model. In other words, if $c / K_{n}$ increases beyond 2 to 15 , then the hux density, which is scaled in accordance with the first part of Eq. (22). will exceed our arbitrary hus pracicical limit of $8 \mathrm{~T}$, as a result of $\lambda>1.2$. The lower limit in the $c / K$ constraint corresponds to the minimu.n rotor radius for which structural stability in the drum-composite structure exists, with a 1.5 factor of safety. Optimization could be carried to $\lambda>$ 1.2 if $\mathrm{B}$ is kept const ant at $8 \mathrm{~T}$; however, this was not done.

Some uncertainty exists in the magnetic flux value $\phi_{0}$, for which the lower limit of the computed values $36.3^{+1.9}$ has been chosen. This results from the uncertain widtl of the collector area, which is a design variable. If the computations leading to the curves plotted in Fig. 18 are repeated for the upper limit, i.e., for $38.2 \mathrm{~Wb}$, we obtain an increase of $0.5 \%$ in $\eta$. leading to $\epsilon=\left\{\begin{array}{l}1.0^{\prime} ; \\ 1\end{array}\right.$ fitting error results in the error bars in Fig. 19. The normalization is treated in Appendix $B$.

The question arose as to how muctr better the elficiency-vs-cost characteristic of a spool machine might be compared with the drum type. A split coil configuration was computed for this purpose. in which the disks extend into the region where the vector potential maximum exists, i.e.. in the space bet ween coil halves when each coil is split in its fluxnormal plane $z=0$. The reference flux increases for this configuration to numbers from $40-42 \mathrm{~Wb}$ if the maximum field in the coils is maintained. This results in an improved $\eta$-vs-c characteristic, plotted in rig. 18, and amounts to an efficiency increase of 1 - $33^{\prime} \%$, which makes possible $\eta=91 \%$ machine for $c=$ $4.4 \mathrm{~d} / \mathrm{J}$ as compared with $5.6 \mathrm{~d} / \mathrm{J}$ for a drum machine with the same efliciency for $\tau_{1 / 2}=3 \mathrm{~ms}$.

Table I gives the characteristic design numbers for $\tau_{1 / 2}=3 \mathrm{~ms}$, corresponding to $\mathrm{N}=36$ and $\mathrm{n}=32$ in Fig. 18. Tabulated are all major problem constants used in the computations leading to the plots of Figs. 18 and 19. The loss and cost elements of one of the tabulated designs, the 13 th line $\left(f_{\text {crele }}=0.9, c=4.84\right.$ d/J), are listed in Table li.

\section{ACKNOWLEDGMENTS}

Useful suggestions on the compression coil's design and structural analysis were contributed by R. Bartholomew. We had many worthwhile discussions with $R$. Krakowski, coordinator of the LTPHR study group, and with $\mathrm{K}$. Thomassen, $\mathrm{G}$. Boicourt, M. Kristiansen, F. Ribe, and H. H. Woodson. Ribe and Woodson were probally lirst to suggest that the compression coil energization might be possible with homopolar machines. Many contributions on gas bearings are from H. G. Rylander. 


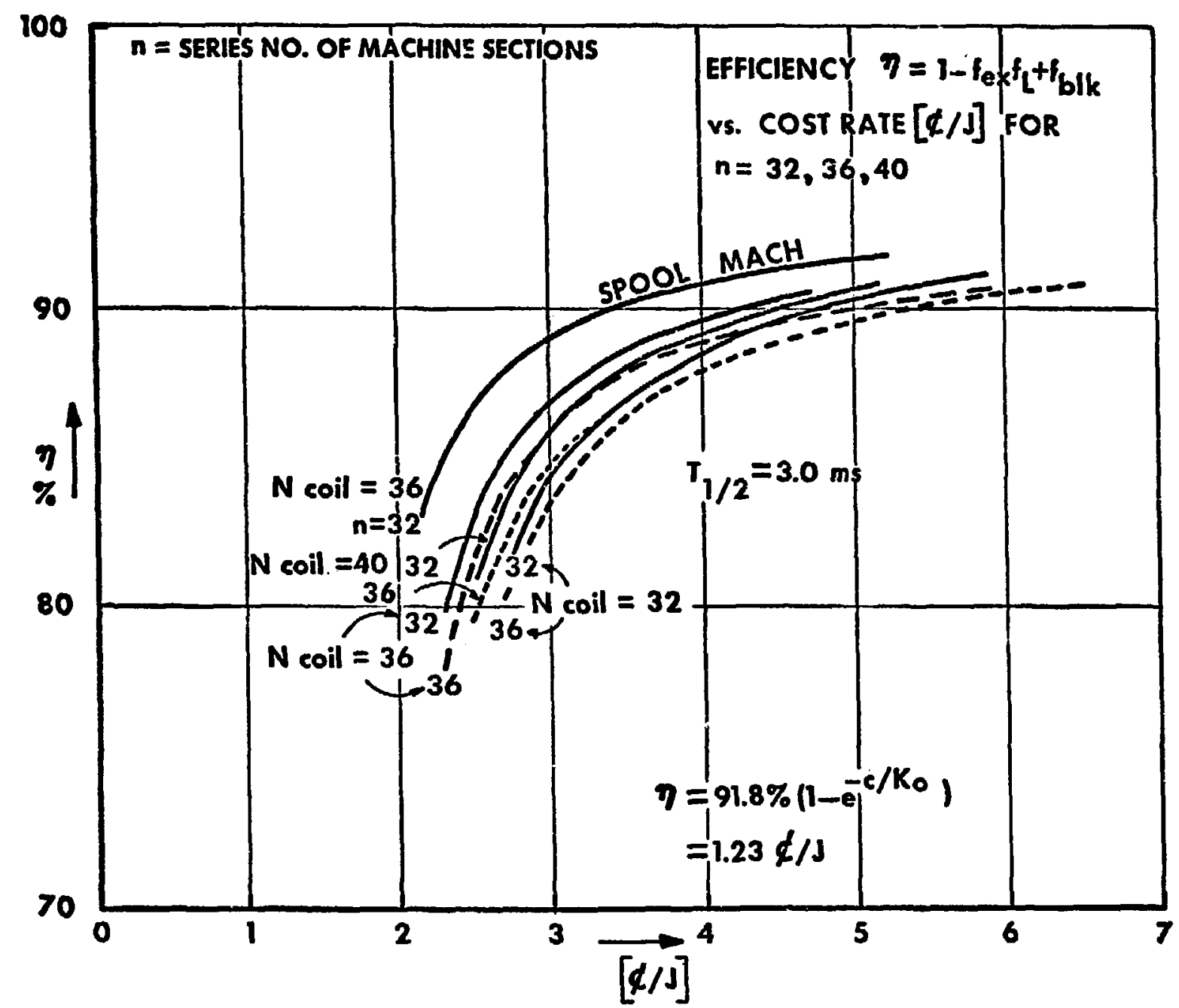

Fig. 18. 


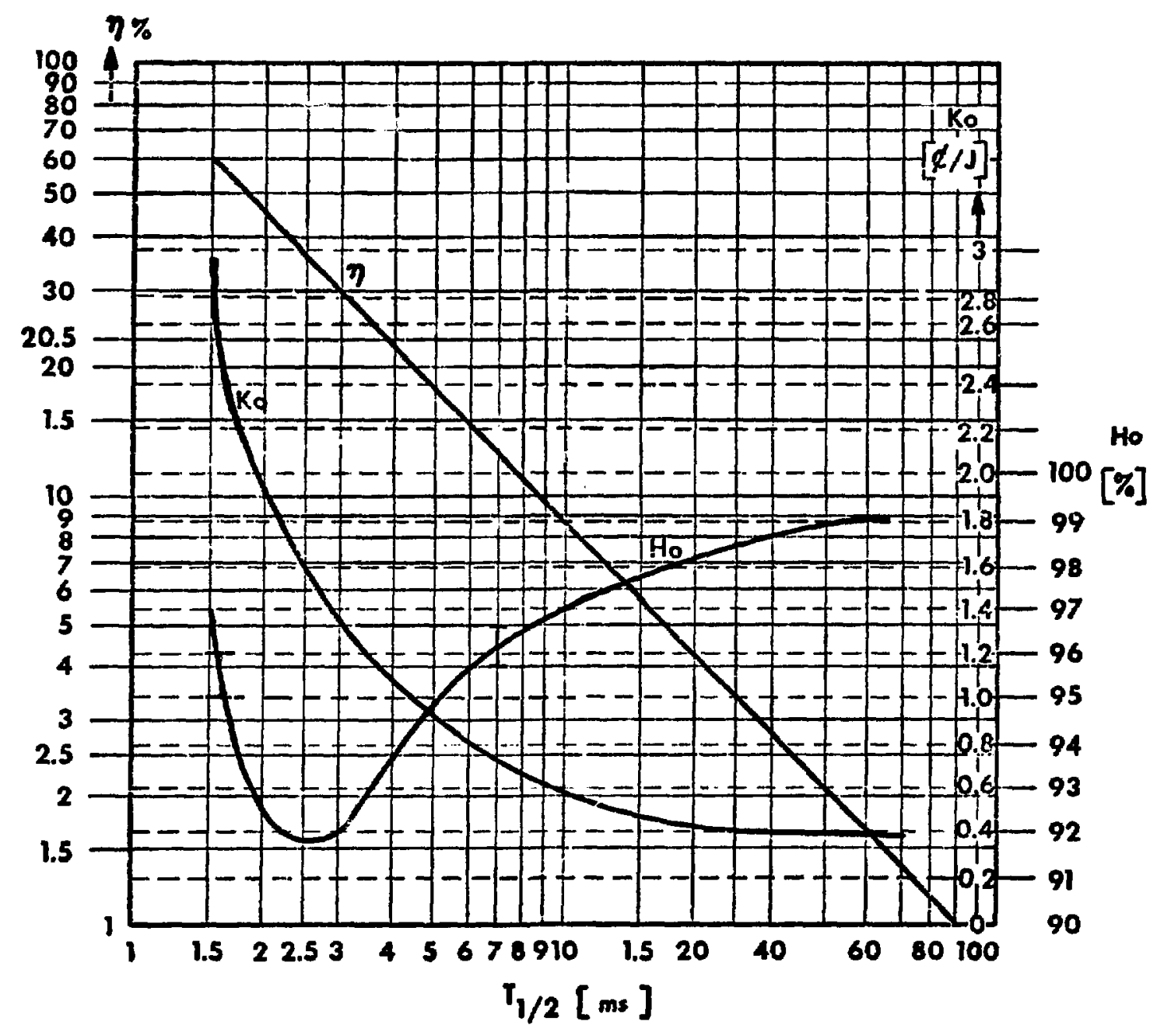

Fig. 19.

Optimization characteristics

$\eta=$ number of machine sections in series

$\mathrm{H}_{1}=$ = efficiency limit

$K_{t}=$ logarithmic cost decrement $v$ s discharge time $\tau_{1 / 2}$. 
TABLE I

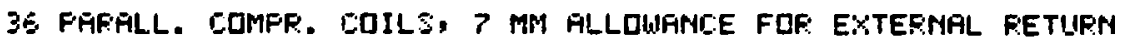

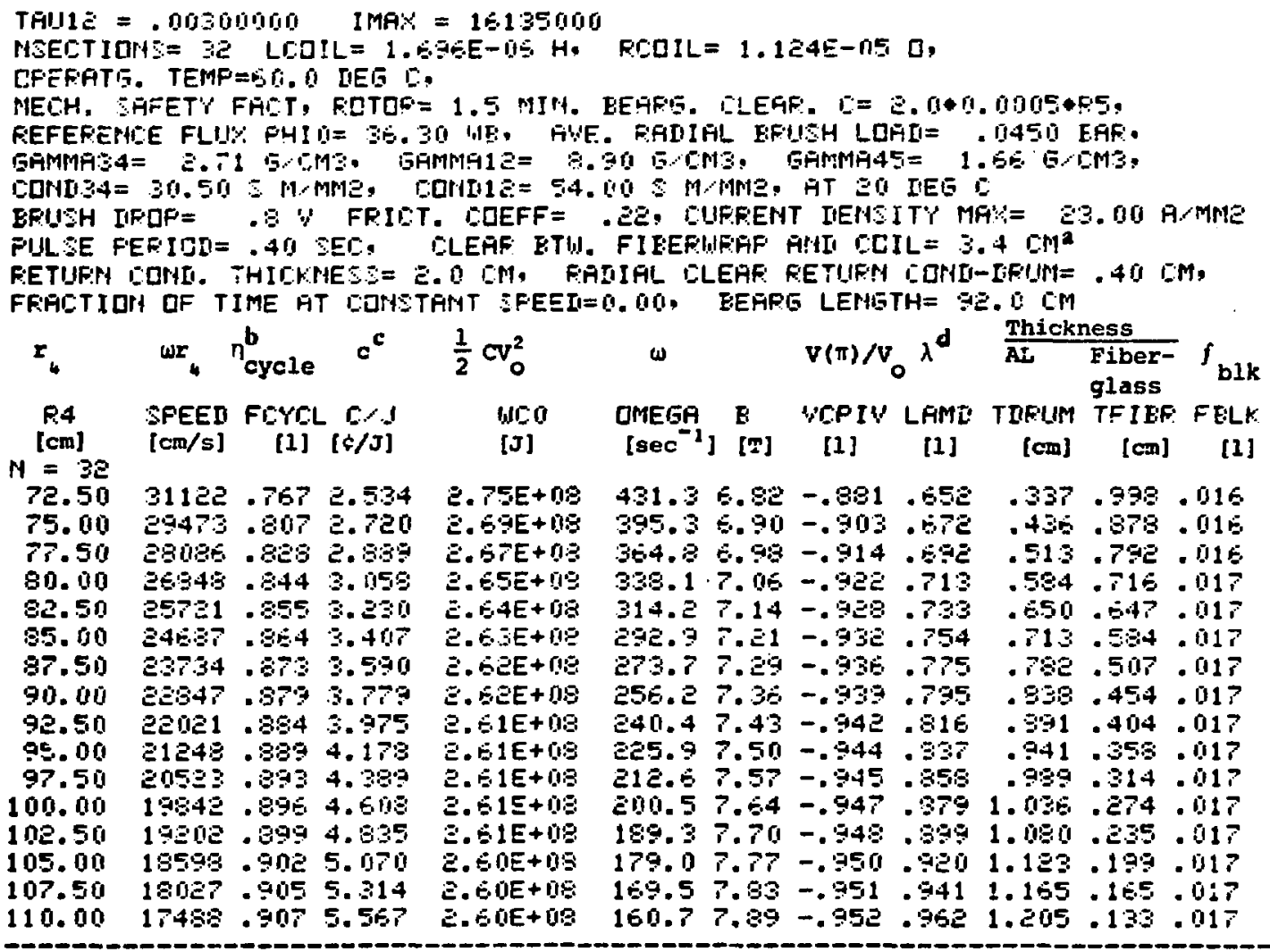

${ }^{a}$ Allowing $0.7 \mathrm{~cm}$ for the outer return conductor.

${ }^{b} \eta_{c y c t h}=1-f_{\text {ex }} f_{L}+f_{b l k}$.

' $T$, be increased by 4 r. for double compensation.

${ }^{d}$ Section length $=228 \lambda \mathrm{cm}$. 
LOSS AND COST SUMMAKY ON THE DHSIGN PEIR TABI.K I.

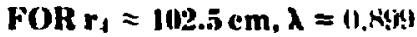

Losses in Per Cent of $\frac{1}{2} \mathrm{CV}_{0}^{2}$ for 0.4-s Pulse

Period

Drum joule loss $\quad$ i...4,

Return conductor joule loss

Brush joule loss (voltage drop)

Brush friction loss ${ }^{\mathrm{a}}$

Bearing loss = windage loss $\quad 0.4$

Refrigeration loss $\quad 11.013$

Power supply loss (charging loss)

Compression c oil loss

Total loss incl. compression coil

Costs in Per Cent of Total Machine Cost

$\operatorname{Iron}\left(\mathrm{nM}_{\mathrm{ro}}\right.$, ske $\left._{\mathrm{F}} / \mathrm{s}_{\mathrm{tut}}\right)=$

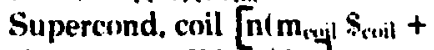

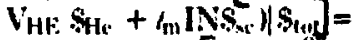

Refrigeration $\left[\mathrm{n} \mathrm{P}_{\mathrm{ref}}\right)^{\left(\mathrm{n}+\mathrm{s}_{\mathrm{ref}}+\right.}$

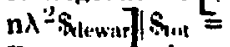

Return conductor, drum (n M. $\left.\$_{d} \mid \$_{t+1,}\right)=$

12.34

Current collection $\left(\mathrm{n}_{13} \mathrm{~S}_{3} \mid \mathrm{S}_{1,1,}\right)=$

44,4

Assembly $(1 \cdot 1 / 1.2)=$

Total machine cost sto.t $=12.4 \mathrm{Ms}$

3.4

6.2

17.1

$\frac{16.1}{1(1)}$

"Assuming that the brushes make cumtart for $9 \mathrm{~ms}$ at an alerage pressure of 0.7 har superposed with an elererorlynamis load peaking at 8 har. 


\section{Atritestots}

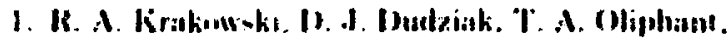

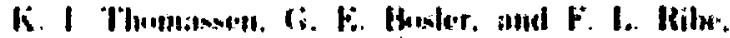

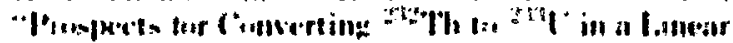

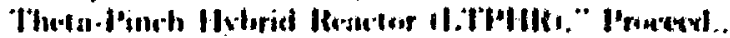

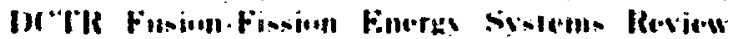

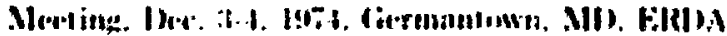

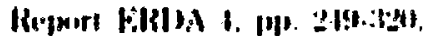

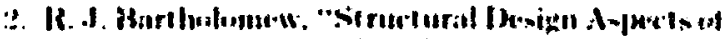

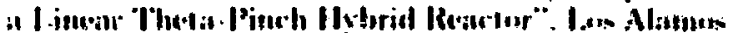

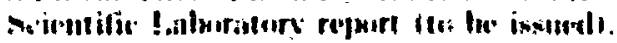

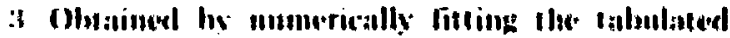

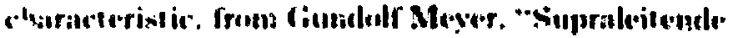

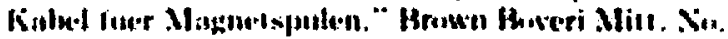

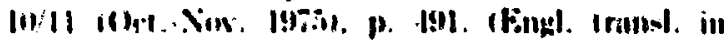

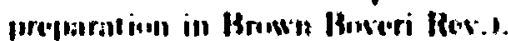

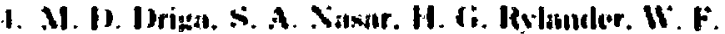

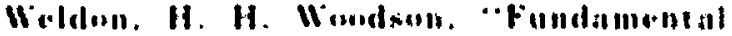

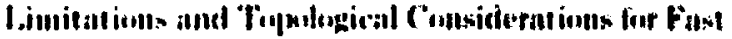

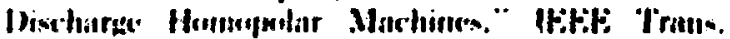

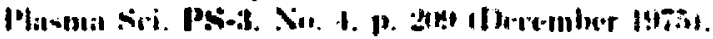

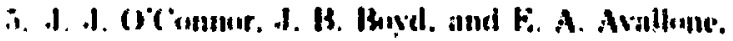
Silandurd llandbook of I.ubrieation linkinecrink Aldirill Hill. Now York. I!Misi.

b. F. F. Misenn and W. J. Aludersmen. "Adsomed

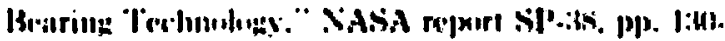
liti I! mit!.
̈. II. Shlititing and f. Kestin. Bnundary Layer

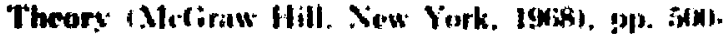
int:

s. 1). J. Ontheff. "The Itemien of a Brian Teat Machine and the "iegificattion of the Machien Diwign

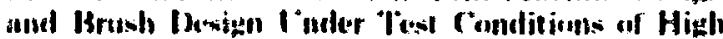

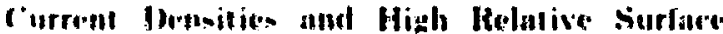

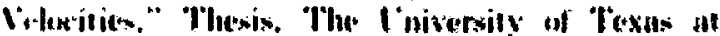
Ansin. Jamuars 197i.

9. W. M1. Kays and F. Y. Leung. "Hent Transfer in

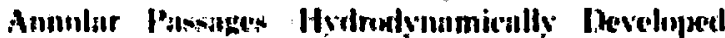

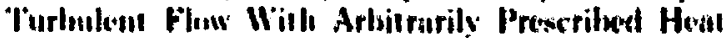

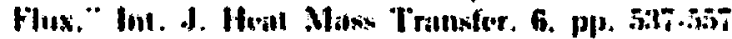
(15m:1,

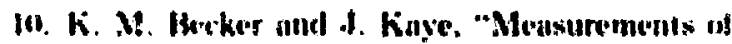
Diabsatic Flus in Annulus with an Inner Rotating Crlinder." J. Hent Tronsfer. Trans. AsMk. \&4. Ser.

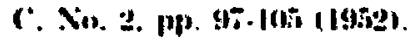

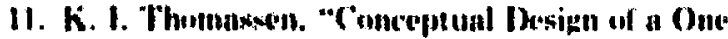
(i.) Fase Discharzimy Honmopsilar Machine for the

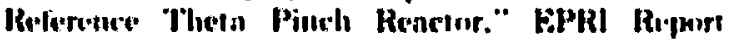

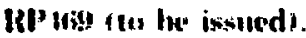

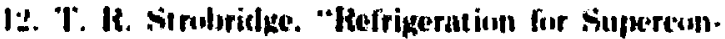

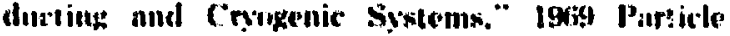

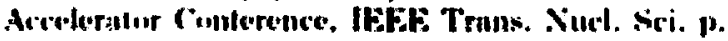
IIII.

\section{APPBNDIX A}

\section{BLFCTROMALNFTIC EXCITATION}

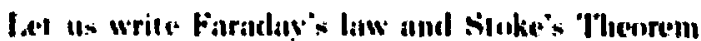

$$
\begin{aligned}
& \vec{\nabla} \times \vec{E}+\frac{\partial B}{\partial t}=0 \\
& \hat{P}_{\vec{E}} \mathrm{~d}=\int_{F}(\vec{\nabla} \times \vec{E}) d f .
\end{aligned}
$$

The potentiul vectur $A$ is delined hy

$$
\vec{\nabla}=\vec{\nabla} \times \vec{A} \text {. }
$$

'The curls drup wu if Fep $(A \cdot 3)$ is subst itued in (A. 11. which vields

$$
\vec{E}+\frac{\partial}{\partial t} \vec{A}=0 .
$$

Integrating Kq. (A-4) with Sitoke's theorem leads to

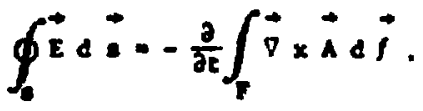

For cylindrital cokrdinates, the right side of Eq. IAi) may he written 


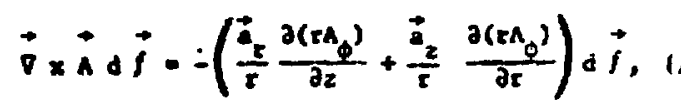

where

$d \vec{f} \cdot \vec{a}_{r} \cdot 2 \pi r d z+\vec{a}_{z} \cdot 2 \pi r d r$.

Carrying out the inner product multiplication in Fa. (A-15) viclds

$$
\int_{F} \times \vec{d} d \vec{f}-2 \pi \int_{F}\left(x A_{\phi}\right)=0,
$$

where os is the Mux through the circle with radius $r$. Substituting Eq. (A-8) in Eq. (A-5) yields $\oint^{+} d \vec{s}=v=-\frac{d \phi}{d t}$

The tot al derisative on the right side of $\mathrm{Fq} .(\mathrm{A}-9)$ is

$\frac{d \phi}{d t}=\frac{\partial \varphi}{\partial t}+v \frac{\partial \phi}{\partial x}$,

where the partial time derivative is zero in this do application, and where $v$ denotes velocity. The velocity with which the tlux linkage in Fig. 10 is changed is $v=d x / d t$. In other words, the flux lines in Fig. 10are lines of const ant vector potential, and the conductor position moves to constantly changing values in this potential field.

\section{APPENDIX B}

\section{NORMALIZATION OF THE EFFICIENCY-VS- DISCHARGE TIME PLOTS}

Let the reference configuration be given by $\mathrm{N}_{1}$ parallel criils with $n_{\text {, }}$ turns each and with reference total current $L_{\text {.. }}$ reference coil tield $B_{i, .}$ and reference effective coil dimensions $r_{n,}$ and $/{ }_{10}$.

We want to know the relationships to be met if a ditferent number of coils $\mathrm{N}$ are paralleled and the tut al current $I=I_{\text {, }}$ and total inductance $I_{0}=L_{\text {, }}$ are to remain the same. We can write

$$
1=\frac{L}{L_{0}}=\frac{H_{0}}{n}\left(\frac{n}{n_{0}}\right)^{2}\left(\frac{r}{r_{0}}\right)^{2}\left(\frac{L_{0}}{r^{\prime}}\right)
$$

and

$1=\frac{I}{I_{0}}=\frac{H}{X_{0}}\left(\frac{B}{B_{0}}\right)\left(\frac{n_{0}}{n}\right) \frac{L}{L_{0}}$.

Fqs. (B.1) and (B.2) require that

$\frac{B}{B_{0}}\left(\frac{\mathrm{r}}{r_{0}}\right)^{2} \frac{n}{n_{0}}=1$

in other words, conservation of $n_{0} r_{0} \pi B_{0}=25 \mathrm{~Wb}$ turns is the premise for this optimization, where $n_{0}$ $=10, \mathrm{r}_{\mathrm{i}}=0.178 \mathrm{~m}, \mathrm{~B}_{\mathrm{n}}=25 \mathrm{~T}$. 